\title{
Advances in coupling of kinetics and molecular scale tools to shed light on soil biogeochemical processes
}

\author{
Donald L. Sparks
}

Received: 14 May 2014 / Accepted: 20 August 2014 / Published online: 2 September 2014

(C) Springer International Publishing Switzerland 2014

\begin{abstract}
Background Biogeochemical processes in soils such as sorption, precipitation, and redox play critical roles in the cycling and fate of nutrients, metal(loid)s and organic chemicals in soil and water environments. Advanced analytical tools enable soil scientists to track these processes in real-time and at the molecular scale.

Scope This review focuses on recent research that has employed state-of-the-art molecular scale spectroscopy, coupled with kinetics, to elucidate the mechanisms of nutrient and metal(loid) reactivity and speciation in soils.

Conclusions By coupling kinetics with advanced molecular and nano-scale tools major advances have been made in elucidating important soil chemical processes including sorption, precipitation, dissolution, and redox of metal(loids) and nutrients. Such advances will aid in better predicting the fate and mobility of nutrients and contaminants in soils and water and enhance environmental and agricultural sustainability.
\end{abstract}

Keywords Kinetics - In-situ molecularscale techniques · Redox $\cdot$ Sorption $\cdot$ Surface precipitation $\cdot$ Light element chemistry

Responsible Editor: Philippe Hinsinger.

D. L. Sparks $(\bowtie)$

Interdisciplinary Science and Engineering Lab, University of Delaware, 221 Academy St., Suite 250A, Newark, DE 19716, USA

e-mail: dlsparks@udel.edu

\section{Introduction}

To accurately predict and model fate/transport, toxicity, speciation (form of), bioavailability, and risk assessment of plant nutrients, toxic metal(loids), nutrients, radionuclides, and organic chemicals in soils, we must have fundamental information at multiple spatial and temporal scales, and our research efforts must be multidisciplinary and interdisciplinary.

With the advent of state-of-the-art analytical techniques, e.g., those that are synchrotron-based, one can elucidate reaction mechanisms at the molecular and nano- scales. There have been extensive reviews on the use of synchrotron-based techniques, including principles, methodology, sample preparation, and data analyses published in the literature (Brown 1990; Manceau et al. 1992; Fendorf et al. 1994; Schulze and Bertsch 1995; O'Day 1999; Bertsch and Hunter 1998; Hunter and Bertsch 1998; Schulze et al. 1999; Brown and Parks 2001; Bertsch and Hunter 2001; Brown and Sturchio 2002; Fenter et al. 2002; Manceau et al. 2002; Kelly et al. 2008; Lombi and Susini 2009; Singh et al. 2010; Ginder-Vogel and Sparks 2010; Grafe et al. 2014) and other techniques such as vibrational spectroscopy (Parikh et al. 2014).

The use of these techniques has played a pivotal role in advancing research in the soil and environmental sciences the past two decades. Their use in soil and environmental research has resulted in a new multidisciplinary field of study that plant and soil scientists are actively involved in - molecular environmental science. Molecular environmental science can be defined as the 
study of the chemical and physical forms and distribution of contaminants in soils, sediments, waste materials, natural waters, and the atmosphere at the molecular level (Sparks 2002).

Another important way to glean information about contaminant interactions in the soil environment is to study the kinetics, or rates of important soil chemical processes, such as sorption, precipitation, dissolution, redox and complexation. In natural systems, one seldom, if ever, reaches equilibrium so the rates of processes ultimately control fate, transport, and bioavailability of pollutants in soil and water environments (Sparks 1989, 2002). Similarly to research in molecular environmental science, major advances have been made in the study of kinetics of soil chemical processes. These include the development of new methodologies that enable the capture of rapid reaction processes (GinderVogel et al. 2009; Ginder-Vogel and Sparks 2010; Landrot et al. 2010; Siebecker et al. 2014). Aspects of these reviews are discussed later.

To provide definitive reaction mechanisms, a combination of kinetics and molecular scale investigations is preferable. The ultimate situation is when one can determine real-time kinetics at the molecular scale. I will not spend time reviewing background material on kinetics of soil chemical processes or molecular scale techniques as these have been exhaustively reviewed before. Rather, the focus of this review is on recent advances in kinetic and molecular scale studies, both non-real time and real-time, to investigate important soil chemical processes that impact the sustainability of soils and the environment. These include: sorption/precipitation dynamics, redox kinetics, and nutrient and carbon cycling processes.

Advances in time-resolved molecular scale techniques

In soil environments, chemical reactions at the mineral/ water interface occur over a range of temporal scales, ranging from microseconds to years. Many important processes (e.g., adsorption, oxidation-reduction, precipitation) occurring at mineral surfaces are characterized by a rapid initial reaction on a time-scale of milliseconds to minutes (Sparks 1989; Scheidegger and Sparks 1996; Sparks 2002; Ginder-Vogel et al. 2009; Landrot et al. 2010; Siebecker et al. 2014). In fact, in some reaction processes, a large part of the reaction process is complete before the first experimental measurement can be made using traditional batch and flow techniques.
Knowledge of these initial reaction rates, where back reactions and secondary reaction products are minimized, allows for determination of "chemical kinetic" rate constants and reaction mechanisms, both of which are necessary to understand environmental chemical processes. Chemical relaxation techniques such as pressure jump (p-jump) and concentration jump (c-jump such as stopped-flow) allow rapid data collection on time scales of milliseconds. However, with chemical relaxation techniques, rate "constants" are calculated from linearized rate equations that include parameters that were determined from equilibrium and modeling studies. Consequently, the rate "constants" are not directly determined (Ginder-Vogel et al. 2009; GinderVogel and Sparks 2010; Sparks 2013).

Direct, in situ, molecular-scale measurement of rapid reactions has, until recently, been quite limited. Fendorf et al. (1993) used stop-flow electron paramagnetic resonance (SF-EPR) spectroscopy to measure Mn(II) sorption to birnessite $\left(\delta-\mathrm{MnO}_{2}\right)$ on a time scale of milliseconds. More recently, Parikh et al. (2008) used in situ, Fourier Transform infrared (FTIR) spectroscopy to measure As(III) oxidation rates by hydrous manganese(IV) oxide (HMO) at a time scale of $\sim 2.5 \mathrm{~s}$. However, both of these techniques suffer from limitations. EPR can only be used to measure EPR active nuclei, while FTIR requires both IR active functional groups and relatively high concentrations of the reactants being examined (Parikh et al. 2008).

Quick-scanning X-ray absorption spectroscopy (Q-XAS) overcomes both of these limitations. Q$\mathrm{XAS}$ is a synchrotron-based technique that allows one to collect and complete a X-ray absorption near edge structure (XANES) or extended X-ray absorption fine structure (EXAFS) spectrum on $\mathrm{ms}$ time scales (Dent 2002).

Depending on beamline instrumentation and photon flux, Q-XAS, can be used to probe elements with atomic numbers $>20$ and at relatively low concentrations (Khalid et al. 2010). The majority of the quickscanning beamlines in the world collect a complete EXAFS scan in $\sim 1$ min or less, by slewing the monochromator from low energy to high energy and repeating the process (Mitsunobu et al., 2006). An alternative method for rapidly collecting EXAFS data is to perform energy-dispersive measurements; however, this technique generally suffers from poor sensitivity and because transmission mode is employed, it may not be suitable for mineral/water investigations (Dent 2002). 
Ginder-Vogel et al. (2009), for the first time, employed Q-XAS to measure the kinetics of As(III) oxidation on hydrous manganese oxide (HMO). A cam-operated, continuously scanning monochromator (Fig. 1) was employed at beamline X18B at the National Synchrotron Light Source (NSLS) at Brookhaven National Laboratory. With this technique one can collect an entire XANES or EXAFS spectrum in 300 and $600 \mathrm{~ms}$, respectively, and also have high sensitivity at low elemental concentrations. The continuous rocking motion permitted the collection of X-ray fluorescence spectra as the monochromator moved from low to high and from high to low energy, which greatly enhanced the time resolution of the XAS measurements.

Q-XAS has been employed over the past several years to study metal sorption/precipitation (Siebecker et al. 2014) and redox kinetics (Ginder-Vogel et al. 2009; Landrot et al. 2010) using both batch and flow apparatus. More details on these studies will be discussed later in the review.

Advances in metal sorption/precipitation/dissolution kinetics and mechanisms at the soil/water interface

Based on traditional macroscopic studies, one can predict that alkaline earth cations, $\mathrm{Mg}^{2+}, \mathrm{Ca}^{2+}, \mathrm{Sr}^{2+}$, and $\mathrm{Ba}^{2+}$ primarily form outer-sphere complexes (Sparks 2002). Numerous molecular scale studies (Sparks 2002) show that the divalent first-row transition metal cations $\mathrm{Mn}^{2+}, \mathrm{Fe}^{2+}, \mathrm{Co}^{2+}, \mathrm{Ni}^{2+}, \mathrm{Cu}^{2+}$, and $\mathrm{Zn}^{2+}$, and the divalent heavy metal cations such as $\mathrm{Cd}^{2+}, \mathrm{Hg}^{2+}$, and $\mathrm{Pb}^{2+}$ primarily form inner-sphere complexes (Table 1 ).

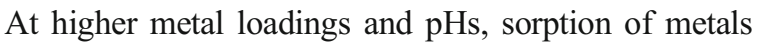

such as $\mathrm{Co}, \mathrm{Cr}, \mathrm{Ni}$, and $\mathrm{Zn}$ on phyllosilicates and metal-(oxyhydr) oxides can result in the formation of surface precipitates (Ginder-Vogel and Sparks 2010; Sparks and Ginder-Vogel 2011). The formation kinetics and mechanisms of these multinuclear and precipitate phases will be discussed in more detail later.

Although there are is a lack of molecular scale data to directly determine the type of surface complexes that the anions $\mathrm{NO}_{3}{ }^{-}, \mathrm{Cl}^{-}$, and $\mathrm{ClO}_{4}{ }^{-}$form on mineral surfaces, one can propose that they are sorbed as outer-sphere complexes and sorbed on surfaces that exhibit a positive charge. Some researchers have also concluded that $\mathrm{SO}_{4}{ }^{2}$ - (Zhang and Sparks 1990) can be sorbed as an outersphere complex; however, there is other direct, spectroscopic evidence that $\mathrm{SO}_{4}{ }^{2-}$ can also be sorbed as an inner-sphere complex (Manceau and Charlet 1994; Hug 1997; Peak et al. 1999; Zhu et al. 2014). While this dispute has not been resolved, environmental factors that are employed in the different studies, e.g., concentration, ionic strength, $\mathrm{pH}$, and time, could cause different interpretations. There is direct spectroscopic evidence to show that selenate can be sorbed as both an outer-sphere and an inner-sphere complex, depending on environmental factors (Hayes et al. 1987; Wijnja and Schulthess 2000).

Most other anions such as molybdate, arsenate, arsenite, selenite, phosphate, and silicate appear to be strongly sorbed as inner-sphere complexes, and sorption occurs through a ligand exchange mechanism (Table 1). The sorption maximum is often insensitive to ionic strength changes. Sorption of anions via ligand exchange results in a shift in the pzc of the sorbent to a more acidic value (Sparks 2002, 2005b).

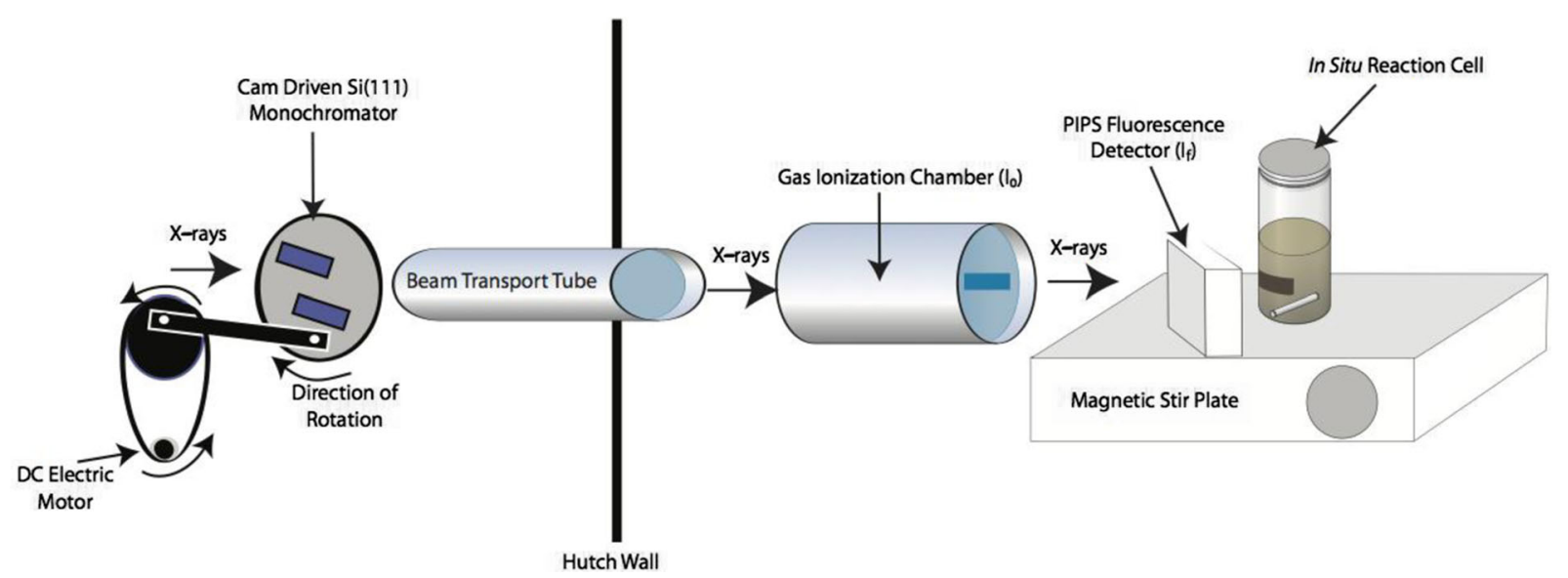

Fig. 1 Experimental setup used to collect Q-XAS data. (Reprinted with permission from Ginder-Vogel et al. 2009) 
Table 1 Predominant sorption mechanisms for metals and metalloids on mineral surfaces

\begin{tabular}{|c|c|}
\hline \multicolumn{2}{|c|}{ Predominant Sorption Mechanism } \\
\hline \multicolumn{2}{|l|}{ Metals } \\
\hline Cadmium & Inner-sphere \\
\hline Cobalt & $\begin{array}{l}\text { Inner-sphere (low loading), } \\
\text { Co-Al hydroxide precipitates } \\
\text { (high loading) }\end{array}$ \\
\hline Chromium & $\begin{array}{l}\text { Inner-sphere (low loading), } \mathrm{Cr} \\
\text { hydroxide precipitates (high loading) }\end{array}$ \\
\hline Copper & Inner-sphere \\
\hline Lead & $\begin{array}{l}\text { Inner-sphere (low loading), Surface polymers } \\
\text { (high loading) }\end{array}$ \\
\hline Nickel & $\begin{array}{l}\text { Inner-sphere (low loading), Ni-Al hydroxide } \\
\text { precipitates (high loading) }\end{array}$ \\
\hline Strontium & Outer-sphere \\
\hline Zinc & $\begin{array}{l}\text { Inner-sphere (low loading), Zn-Al hydroxide } \\
\text { precipitates (high loading) }\end{array}$ \\
\hline \multicolumn{2}{|l|}{ Metal(loids) } \\
\hline Arsenite & Inner-sphere \\
\hline Arsenate & Inner-sphere \\
\hline Borate & Inner-sphere \\
\hline Carbonate & Inner-sphere \\
\hline Chromate & Inner-sphere \\
\hline Phosphate & Inner-sphere \\
\hline Selenate & Outer-sphere \\
\hline Selenite & Inner-sphere \\
\hline Sulfate & Outer-sphere \\
\hline
\end{tabular}

These are the predominant sorption mechanisms that form on mineral surfaces based on surface spectroscopy (e.g., XAS and FTIR) studies. However, environmental factors such as $\mathrm{pH}$, surface loading, time, and ionic strength can affect the type of surface complex and there may be multiple surface products that occur on a particular mineral

References for each metal(loid) can be found in Sparks (2002). (Reprinted with permission from Ginder-Vogel and Sparks 2010)

Environmental factors such as $\mathrm{pH}$, surface loading, ionic strength, type of sorbent, and time also all affect the type of sorption complex or product.

As the amount of metal cation or anion sorbed on a surface (surface coverage or loading, which is affected by the $\mathrm{pH}$ at which sorption occurs) increases, sorption can proceed from mononuclear adsorption to surface precipitation (a three dimensional phase). Coprecipitate formation is most limited by the rate of mineral dissolution, rather than the lack of thermodynamic favorability (McBride 1994; Scheidegger et al. 1998). If the formation of a precipitate occurs under solution conditions that would, in the absence of a sorbent, be undersaturated with respect to any known solid phase, this is referred to as surface-induced precipitation (Towle et al. 1997; Sparks 2005a; Borda and Sparks 2008; GinderVogel and Sparks 2010).

Thus there can be a continuum between surface complexation (adsorption) and surface precipitation. At low surface coverages, surface complexation (e.g., outer- and inner-sphere adsorption) tends to dominate. As surface loadings increase, nucleation occurs and results in the formation of distinct entities or aggregates on the surface. As surface loadings increase further, surface precipitation becomes the dominant mechanism.

Using in-situ bulk XAS, it has been shown by a number of scientists that multinuclear metal hydroxide complexes and surface precipitates of $\mathrm{Co}^{2+}, \mathrm{Cr}^{3+}, \mathrm{Cu}^{2+}, \mathrm{Ni}^{2+}$, and $\mathrm{Pb}^{2+}$ can form on metal oxides, phyllosilicates, soil clays, and soils (see references in Sparks and Ginder-Vogel 2011). These metal hydroxide phases occur at metal loadings below theoretical monolayer coverage and in a $\mathrm{pH}$ range well below the $\mathrm{pH}$ where the formation of metal hydroxide precipitates would be expected, according to the thermodynamic solubility product (Scheidegger and Sparks 1996; Sparks 2002, 2005b; Borda and Sparks 2008, GinderVogel and Sparks 2010).

Scheidegger et al. (1997) were the first to show that sorption of metals, such as $\mathrm{Ni}$, on an array of phyllosilicates and Al-oxide, could result in the formation of mixed metal-Al hydroxide surface precipitates, which appear to be coprecipitates. The precipitate phase shares structural features common to the hydrotalcite group of minerals and the layered double hydroxides (LDH) observed in catalyst synthesis. The LDH structure is built of stacked sheets of edge-sharing metal octahedra, containing divalent and trivalent metal ions separated by anions between the interlayer spaces. The general structural formula can be expressed as $\left.\left[\mathrm{Me}^{2+} \mathrm{Me}_{\mathrm{x}}{ }^{3+}(\mathrm{OH})_{2}\right]^{\mathrm{x}+} \cdot(\mathrm{x} / \mathrm{n}) \mathrm{A}^{\mathrm{n}}-\mathrm{mH}_{2} \mathrm{O}\right]$, where for example, $\mathrm{Me}^{2+}$ could be $\mathrm{Mg}(\mathrm{II}), \mathrm{Ni}(\mathrm{II}), \mathrm{Co}(\mathrm{II})$, $\mathrm{Zn}(\mathrm{II}), \mathrm{Mn}(\mathrm{II})$, and $\mathrm{Fe}(\mathrm{II})$ and $\mathrm{Me}^{3+}$ is $\mathrm{Al}(\mathrm{III})$, $\mathrm{Fe}(\mathrm{III})$, and $\mathrm{Cr}(\mathrm{III})$ (Towle et al. 1997). The LDH structure exhibits a net positive charge $\mathrm{x}$ per formula unit which is balanced by an equal negative charge from interlayer anions $\mathrm{A}^{\mathrm{n}-}$, such as $\mathrm{Cl}^{-}$, 
$\mathrm{Br}^{-}, \mathrm{I}^{-}, \mathrm{NO}_{3}{ }^{-}, \mathrm{OH}^{-}, \mathrm{ClO}_{4}{ }^{-}$, and $\mathrm{CO}_{3}{ }^{2-}$; water molecules occupy the remaining interlayer space (Taylor 1984). The minerals takovite, $\mathrm{Ni}_{6}$ $\mathrm{Al}_{2}(\mathrm{OH})_{16} \quad \mathrm{CO}_{3} \cdot \mathrm{H}_{2} \mathrm{O}$ and hydrotalcite, $\mathrm{Mg}_{6}$ $\mathrm{Al}_{2}(\mathrm{OH})_{16} \mathrm{CO}_{3} \cdot \mathrm{H}_{2} \mathrm{O}$ are among the most common natural mixed-cation hydroxide compounds containing Al (Taylor 1984; Sparks 2005b; Borda and Sparks 2008). Recently, Livi et al. (2009), using an array of microscopic techniques including analytical electron microscopy (AEM), high resolution transmission electron microscopy (HRTEM), and powder X-ray diffraction, conducted studies to elucidate the nature of $\mathrm{Ni}$ hydroxide precipitates, using the same environmental conditions employed by Scheidegger et al. $(1996,1997)$ and reaction times ranging from $1 \mathrm{~h}$ to 5 years. While the precipitate phase had a bonding environment similar to $\mathrm{Ni}-\mathrm{Al} \mathrm{LDH}$, the precipitate was amorphous.

Mixed Co-Al and $\mathrm{Zn}-\mathrm{Al}$ hydroxide surface precipitates also can form on aluminum-bearing metal oxides and phyllosilicates (Towle et al. 1997; Thompson et al. 1999a, b; Ford and Sparks 2000). This is not surprising, as $\mathrm{Co}^{2+}(0.75 \mathrm{~A}), \mathrm{Zn}^{2+}(0.74 \mathrm{~A})$, and $\mathrm{Ni}^{2+}(0.69 \mathrm{~A})$ all have similar radii to $\mathrm{Al}^{3+}(0.54 \mathrm{~A})$, enhancing substitution in the mineral structure and formation of a coprecipitate. However, surface precipitates have not been observed with $\mathrm{Pb}^{2+}$, as $\mathrm{Pb}^{2+}$ is too large $(1.19 \mathrm{~A})$ to substitute for $\mathrm{Al}^{3+}$ in mineral structures (Sparks 2002, 2005b; Borda and Sparks 2008; Ginder-Vogel and Sparks 2010).

The mechanism for the formation of metal hydroxide surface precipitates is not clearly understood. It is clear that the type of metal ion determines whether metal hydroxide surface precipitates form, and the type of surface precipitate formed, i.e., metal hydroxide or mixed metal hydroxide, is dependent on the sorbent type. Additionally, the reaction $\mathrm{pH}$, which controls the degree of metal loading, is also a major factor in determining the formation of metal hydroxide precipitates. Sparks and his group have shown that below pH 6.5, metal hydroxide precipitates do not form on mineral surfaces or in soils in laboratory studies (Elzinga and Sparks 1999; Roberts et al. 1999; Elzinga and Sparks 2001; Roberts et al. 2003).

$\mathrm{Li}$ et al. (2012) recently studied mechanisms of $\mathrm{Zn}-\mathrm{Al}$ LDH formation on aluminum oxide, using a combination of EXAFS, HRTEM, synchrotron-based radiation powder X-ray diffraction (SR-XRD) and ${ }^{27} \mathrm{Al}$ solidstate nuclear magnetic resonance (NMR) spectroscopy.
EXAFS analyses showed the formation of $\mathrm{Zn}-\mathrm{Al} \mathrm{LDH}$ precipitate phases at a $\mathrm{Zn}$ concentration $>0.4 \mathrm{mM}$ (Fig. 2). The NMR analyses provided direct evidence for the presence of $\mathrm{Al}$ in the precipitates and migration due to the dissolution of the alumina substrate. The latter was also suggested by studies on a series of $\mathrm{Al}$ (hydr) oxides with similar chemical composition to the alumina used in the studies, but differing in their dissolution behavior. Sorption samples were prepared using the same experimental conditions as for the alumina surface, i.e., a $\mathrm{Zn}$ concentration of $0.8 \mathrm{mM}$ at $\mathrm{pH} 7.5$ and a reaction time of $15 \mathrm{~min}$. The latter was based on results that showed that the formation of the $\mathrm{Zn}-\mathrm{Al} \mathrm{LDH}$ precipitates occurred on corundum and gamma-alumina within $15 \mathrm{~min}$. Figure 3 shows that LDH phases formed on alumina and corundum as suggested by the two features at about 7.2 and $9.5 \AA^{-1}$ in the chi functions and the appearance of a second shell in the radial distribution function (Fig. 3). The EXAFS spectra for boehmite, bayerite, and gibbsite sorbed samples do not show formation of $\mathrm{Zn}-\mathrm{LDH}$ phases, but rather inner-sphere adsorption complex formation. The finding that precipitate formation is strongly correlated with the dissolution propensity of the mineral surface, i.e., the dissolution order is alumina $>$ corundum $>$ bayerite $>$ boehmite $>$ gibbsite, strongly indicates that the dissolution of the mineral, particularly the dissolution of $\mathrm{Al}$, is an important mechanism in LDH formation.

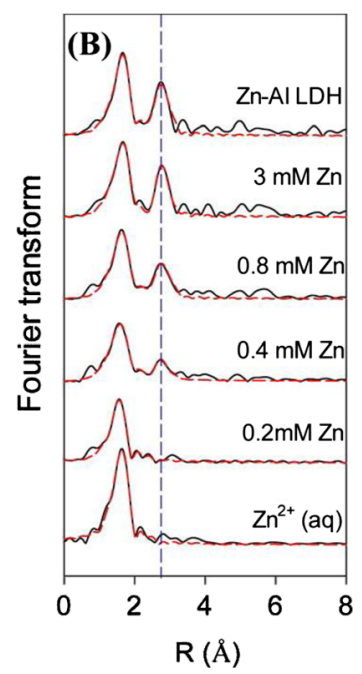

Fig. 2 EXAFS analysis of $\mathrm{Zn}$ adsorption/precipitation on $\gamma$ alumina showing Fourier transform (phase shift not corrected) data. Experimental and fitted data are presented as black solid lines and red dashed lines, respectively. (Reprinted with permission from Li et al. 2012) 

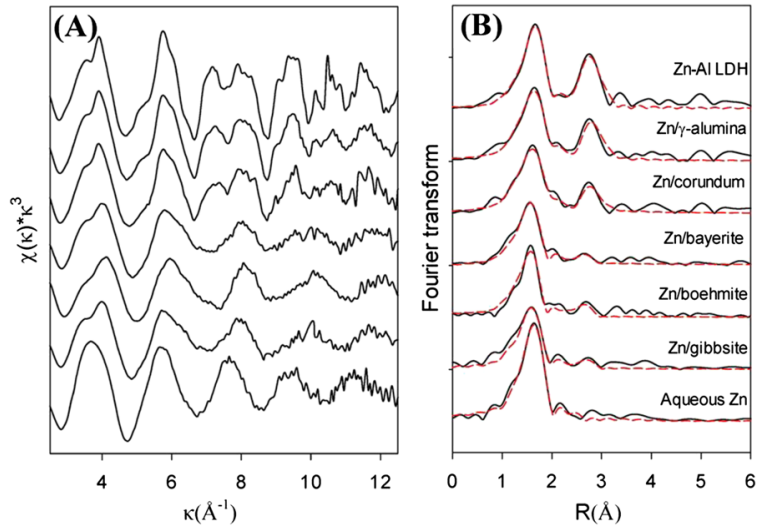

Fig. 3 EXAFS analysis of $\mathrm{Zn}$ adsorption/precipitation on different $\mathrm{Al}$ (hydr)oxides. a $k^{3}$ weighted $\chi$ functions; $\mathbf{b}$ the corresponding Fourier transform (phase shift not corrected). Experimental and fitted data are presented as black solid lines and red dashed lines, respectively. (Reprinted with permission from Li et al. 2012)

The formation of metal LDHs also play a significant role in sequestering metals such as $\mathrm{Co}, \mathrm{Ni}$, and $\mathrm{Zn}$ in soils. As the surface precipitates age, metal release is greatly reduced. Thus, the metals are less prone to leaching and being taken up by plants and microbes. Peltier et al. (2009) reacted three soils of varying mineralogy and organic matter content with $3 \mathrm{mM} \mathrm{Ni}$ at two pHs, 6 and 7.5, and evaluated Ni bioavailability using a biosensor. At $\mathrm{pH} \mathrm{6,} \mathrm{where} \mathrm{surface} \mathrm{precipitates} \mathrm{did} \mathrm{not}$ form, most of the Ni was bioavailable. However, at $\mathrm{pH} 7.5$, where precipitates were observed to form from XAS analyses, Ni bioavailability was markedly reduced (Ginder-Vogel and Sparks 2010; Sparks and GinderVogel 2011).

The decrease in metal release and bioavailability is linked to the increasing silication of the interlayer of the LDH phases with increased residence time, resulting in a mineral transformation from a LDH phase to a precursor phyllosilicate surface precipitate (Ford et al. 1999; Ford and Sparks 2000). The mechanism for this transformation is thought to be due to diffusion of $\mathrm{Si}$, originating from weathering of the sorbent, into the interlayer space of the $\mathrm{LDH}$, replacing the anions such as $\mathrm{NO}_{3}{ }^{-}$. Polymerization and condensation of the interlayer $\mathrm{Si}$ slowly transforms the $\mathrm{LDH}$ into a precursor metal-Al phyllosilicate. This mechanism of metal stability was definitively confirmed by Peltier et al. (2006), who used acid-solution calorimetry and results from previous calorimetry studies, to show that the enthalpy of formation of $\mathrm{LDH}$ phases is more exothermic, indicating great stability, in the order of $\mathrm{Cl}<\mathrm{N}_{3}{ }^{-}<\mathrm{SO}_{4}{ }^{2-}<\mathrm{CO}_{3}{ }^{2-}<\mathrm{Si}^{4+}$ of
Fig. 5 a) $\mu$-SXRF tricolor maps for the treated soil samples. The numbers indicate the spots where $\mu$-EXAFS spectra were collected. Red is indicative of the distribution of iron, green of copper and blue of zinc. b) $\mu$-EXAFS spectra from selected spots on thin sections from the treated soil. c) $\mu$-SXRF tricolor maps for the non-treated soil samples. d) $\mu$-EXAFS spectra from selected spots on thin sections from the non-treated soil. The solid line indicates the raw $\mathrm{k}^{3} \mathrm{c}(\mathrm{k})$ data and the dotted line indicates the best fits obtained with a linear fitting approach. (Reprinted with permission from Ginder-Vogel and Sparks 2010)

interlayer anionic composition, and that LDH phases were much more stable than a $\mathrm{Ni}(\mathrm{OH})_{2}$ phase.

Until now, detailed studies on the kinetics of LDH formation were very limited (Scheidegger et al. 1998). Traditionally, it has been thought that surface precipitation of metals necessitates longer times. However, in an elegant study, employing Q-XAS, employing a flow technique, Siebecker et al. (2014) have shown that mixed Ni-Al LDH phases on pyrophyllite can occur as quickly as 6-15 $\mathrm{min}$ (Fig. 4). These results suggest that adsorption and precipitation could occur on similar time scales and perhaps concurrently. Thus, there can be a continuum in sorption processes, which dictates that more robust sorption models need development that capture multiple sorption processes over reaction time.

In short, with time, metal sorption on soil minerals can often result in a continuum of processes, from adsorption to precipitation to solid phase transformation, particularly in the case of certain metals, such as $\mathrm{Co}^{2+}, \mathrm{Ni}^{2+}$, and $\mathrm{Zn}^{2+}$. The formation of metal surface precipitates could be an important mechanism for sequestering metals in soils, such that they are less mobile

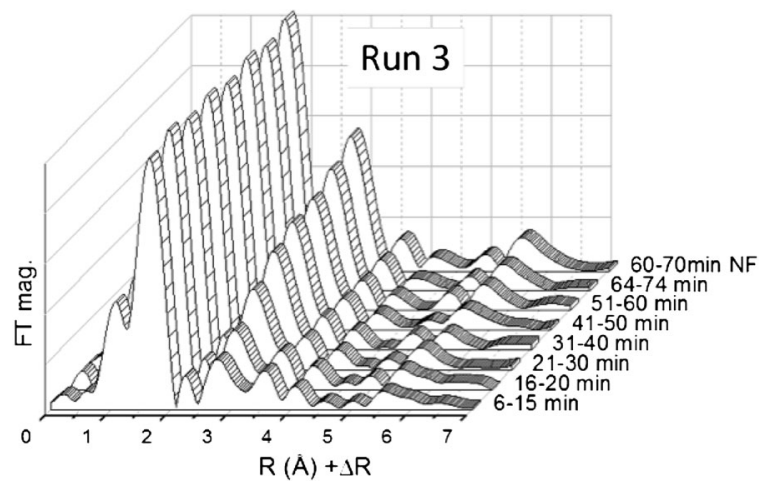

Fig. 4 The radial structure function (RSF) of Run 3, uncorrected for phase shift. During the reaction, the amplitude of the first shell at $\sim 1.6 \AA$ remains constant while that of the second shell at $\sim 2.65 \AA$ increases. The second shell is dynamic over time in all samples, increasing in amplitude and changing slightly in distance and backscatterer coordination number $(\mathrm{CN})$. (Siebecker et al. 2014) 
a

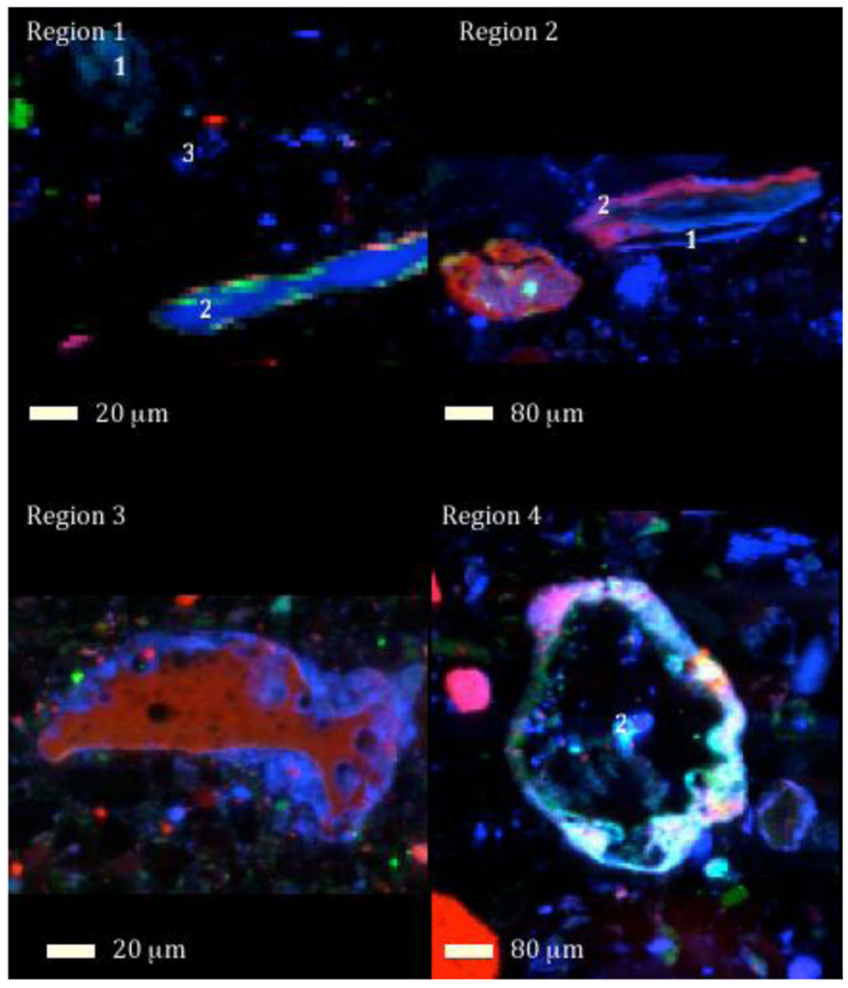

c

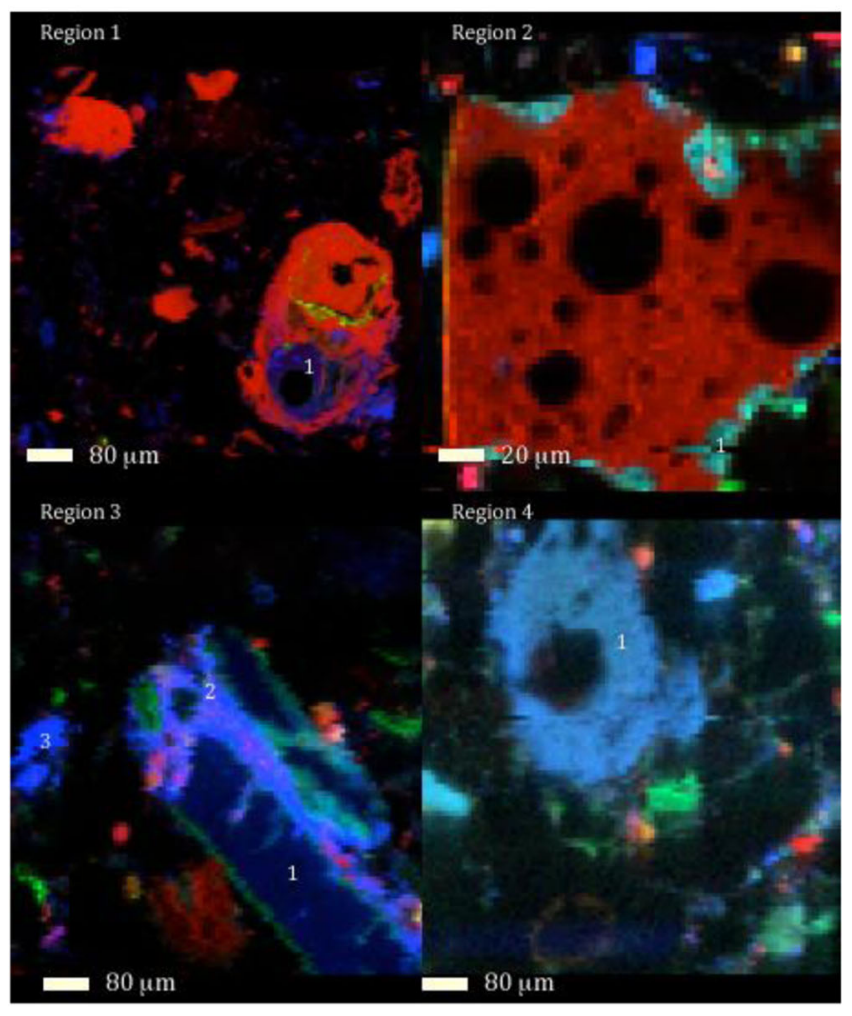

b

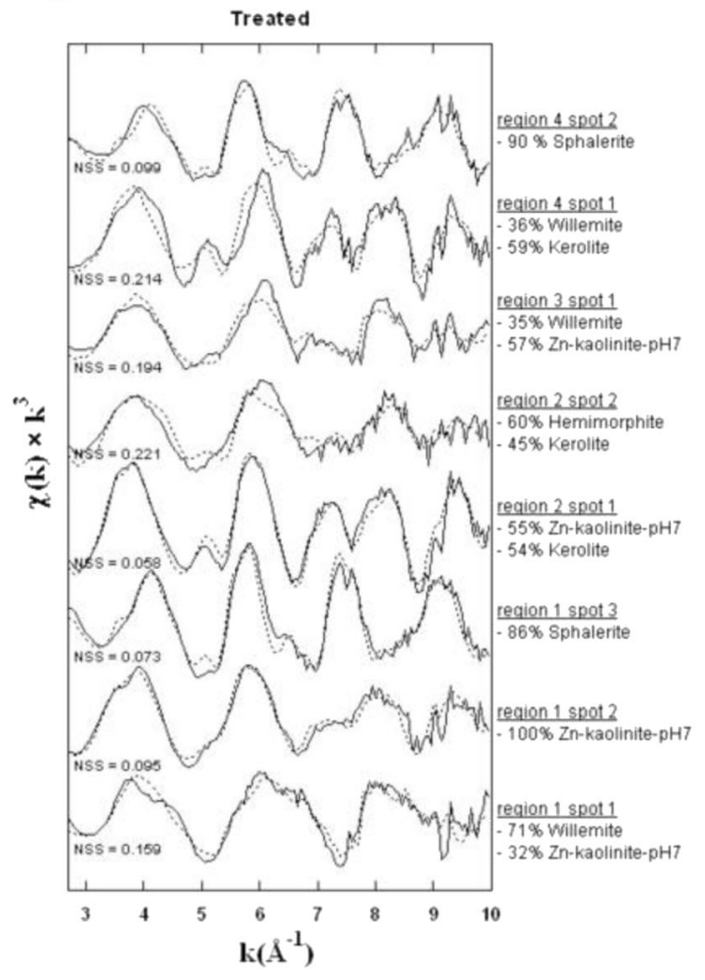

d

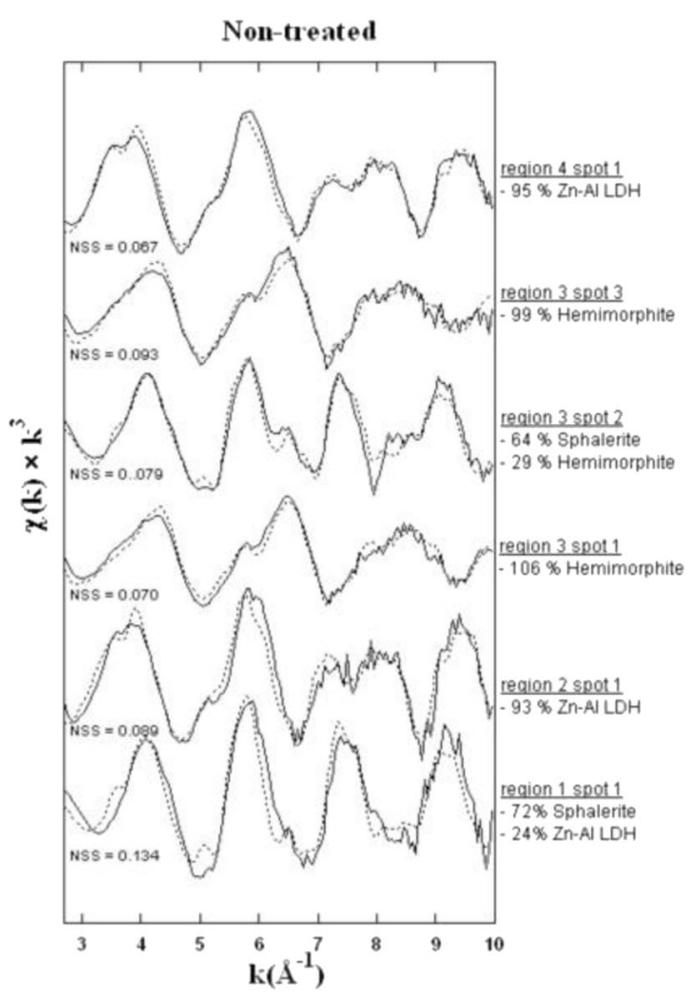


and bioavailable. Such products must be considered when modeling the fate and mobility of metals like $\mathrm{Co}^{2+}, \mathrm{Mn}^{2+}, \mathrm{Ni}^{2+}$, and $\mathrm{Zn}^{2+}$ in soil and water environments (Sparks 2002, 2005b; Borda and Sparks 2008; Ginder-Vogel and Sparks 2010).

Nachtegaal et al. (2005), Juillot et al. (2003), and Voegelin and Kretzschmar (2005) investigated the speciation of $\mathrm{Ni}$ and $\mathrm{Zn}$ in soils. Nachtegaal et al. (2005) employing $\mu$-XAS and $\mu$-XRF, investigated Zn speciation in soils from a large smelter contaminated site in Belgium in which part of the site had been remediated by adding beringite, an aluminosilicate material, compost, and planting metal tolerant plants. The other portion of the site was not treated. The objectives of the study were to determine how Zn speciation differed in the remediated (treated) and non-remediated (nontreated) soils. Specifically the study sought to determine if $\mathrm{Zn}-\mathrm{LDH}$ phases were present in the soils, and the stability of the zinc under different environmental conditions.

A large number of $\mu$-XAS spectra for the treated (Fig. 5b) and non-treated (Fig. 5d) soils were collected at various regions of interest from the XRF spectra (Fig. 5a, treated and Fig. 5c, non-treated soils), as well as spectra for reference mineral, sorbed, and solution phases that were probable species in the soils. The $\mu$-XAS spectra of the soils were analyzed via PCA (i.e., principle component analysis). Target transformation was then employed to determine spoil values for the known reference materials. The spoil value indicates how well the reference spectrum is matched to the principal components. The lower the spoil value, the better the match, and the more likely the reference material is contained in the soil sample. After the contributing standard phases are identified, linear least squares fitting (LLSF) is used to determine the amount (\%) of each standard species within the individual sample spectra making up the dataset. Additional details on $\mu$ XAS applications and data analyses methods for heterogeneous systems can be found in Bertsch and Hunter (2001) and Manceau et al. (2000).

In the study of Nachtegaal et al. (2005) both mineral (e.g., willemite, hemimorphite, spalerite) and sorbed (Zn-LDH) Zn species predominated in the treated and non-treated soils. The speciation differences in the treated and non-treated soils were slight, with the major difference being the presence of kerolite, a $\mathrm{Zn}$ phyllosilicate phase, found in the treated soil (Fig. 5b). Significant quantities of $\mathrm{Zn}-\mathrm{LDH}$ phases were formed in the non-treated soil (Fig. 5d). Desorption studies, using both $\mathrm{CaCl}_{2}$ and $\mathrm{HNO}_{3}$ at $\mathrm{pH} 4$ and 6, showed that the $\mathrm{Zn}$ in both remediated and non-remediated soils was quite stable, reflecting again the role that metal surface precipitates, i.e., Zn-LDH phases, play in sequestering metals such that mobility and bioavailability are diminished.

Similar Ni LDH phases were found in smelter contaminated soils of Port Colborne, Canada in the study of McNear et al. (2007).

In a recent paper, Khaokaew et al. (2012) studied zinc speciation in Cd-Zn co-contaminated alkaline and acidified paddy soils from the Mae Sot district of Tak province of Thailand under different flooding periods and draining conditions, using synchrotron-based techniques and kinetic analyses. In the air-dried and flooded alkaline and acidified soils two major $\mathrm{Zn}$ phases were found, Zn-LDH phases and Zn-phyllosilicates (Fig. 6). The predominant $\mathrm{Zn}-\mathrm{LDH}$ phase was a $\mathrm{Zn}-\mathrm{Mg}$ hydrotalcite phase and the dominant $\mathrm{Zn}$-phyllosilicate phase was a $\mathrm{Zn}$-kerolite. The presence of these phases could explain the low bioavailability of $\mathrm{Zn}$ in the soils. Less than $22 \%$ of $\mathrm{Zn}$ was desorbed from the soils after flooding for two different periods and draining to saturation or field capacity.

\section{Kinetics of redox reactions on soil components}

The mobility and environmental threat of many contaminants and nutrients is determined in large part by their redox state and the redox conditions of the soil environments in which they exist. XAS is an ideal tool for determining the oxidation states of elements in complex environmental media including soils and sediments. In addition, if a change in the element's local coordination environment occurs, it is manifested in EXAFS spectra of the element (Ginder-Vogel and Sparks 2010).

The environmental prevalence of iron and manganese oxides, hydroxides, and oxyhydroxides [(hydr)oxides], coupled with their highly reactive surface areas, make them an important pool of reactivity, with regard to contaminant and nutrient absorption and redox transformation. However, their reactivity, in terms of both sorption and redox chemistry, is radically altered by changes in redox conditions, especially as they impact mineralogy and surface chemistry of iron and manganese oxide phases (Ginder-Vogel and Sparks 2010).

Lafferty et al. (2010a, b, 2011), employing a combined kinetic and molecular scale approach probed the rates and mechanisms of As(III) oxidation on hydrous 


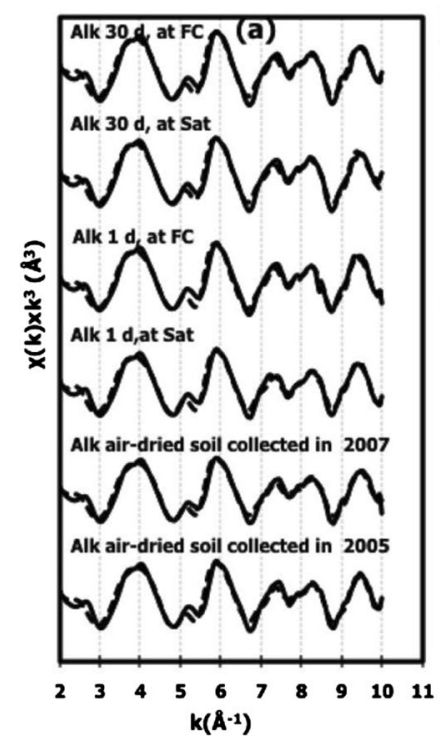

Fig. 6 Linear least-squares fitting results for bulk-XAFS spectra of the $\mathbf{a}$ alkaline soil (Alk) and $\mathbf{b}$ the acidified (Acid) soil, air-dried or flooded for different periods ( $\mathrm{d}=$ days), and drained to saturation (Sat) or field capacity (FC). Solid lines represent the $k^{3}$-weighted

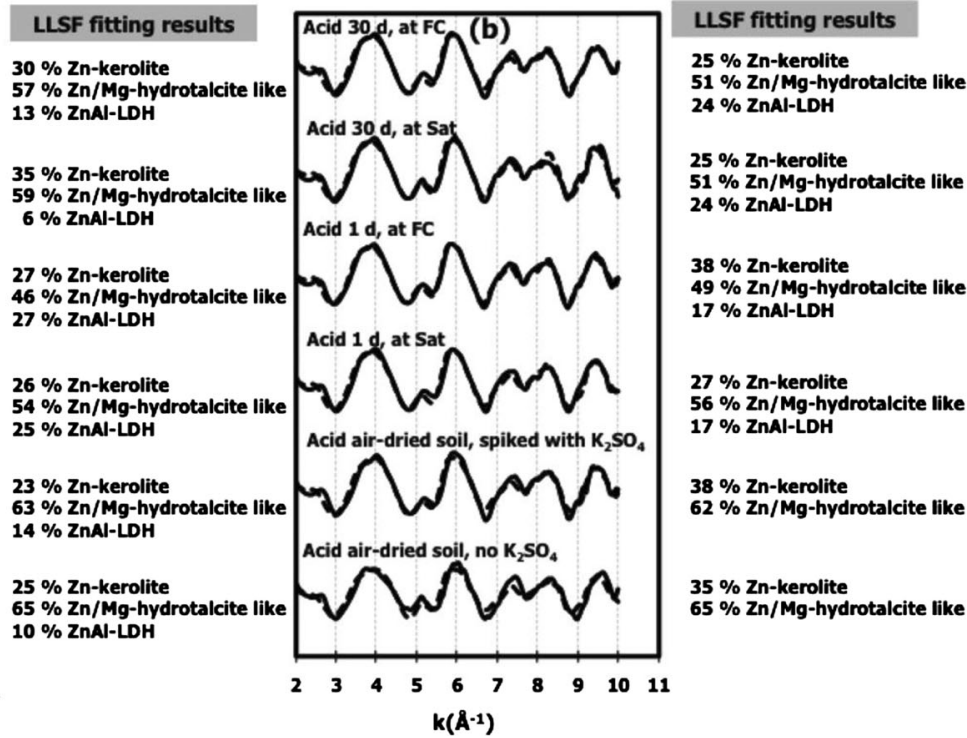

$\chi$-spectra and the dotted line represents the best fits obtained using linear least-squares fitting. (Reprinted with permission from Khaokaew et al. 2012)

in the effluent solution indicating that all the As(III) was oxidized to $\mathrm{As}(\mathrm{V})$ and bound to the HMO or was desorbed into the solution phase. After $6.4 \mathrm{~h}, \mathrm{As}(\mathrm{V})$, as well as $\mathrm{Mn}(\mathrm{II})$ and $\mathrm{As}(\mathrm{III})$ appeared in the effluent. This was also a time when As(III) oxidation decreased. Synchrotron-based XRD and XAS analyses of Mn revealed that initially Mn was sorbed into vacancy sites of the $\mathrm{HMO}$ as both $\mathrm{Mn}(\mathrm{II})$ and $\mathrm{Mn}(\mathrm{III})$, and at between 4
Fig. 7 The amount (nmol) of As sorbed as well as amounts (nmol) of $\mathrm{As}(\mathrm{III}), \mathrm{As}(\mathrm{V})$, and $\mathrm{Mn}(\mathrm{II})$ in the effluent of a stirred-flow experiment reacting $1 \mathrm{~g} / \mathrm{L} \delta-\mathrm{MnO}_{2}$ with $100 \mu \mathrm{M}$ As(III) flowing at $1 \mathrm{~mL} / \mathrm{min}$ for $48 \mathrm{~h}$. (Reprinted with permission from Lafferty et al. 2010a)

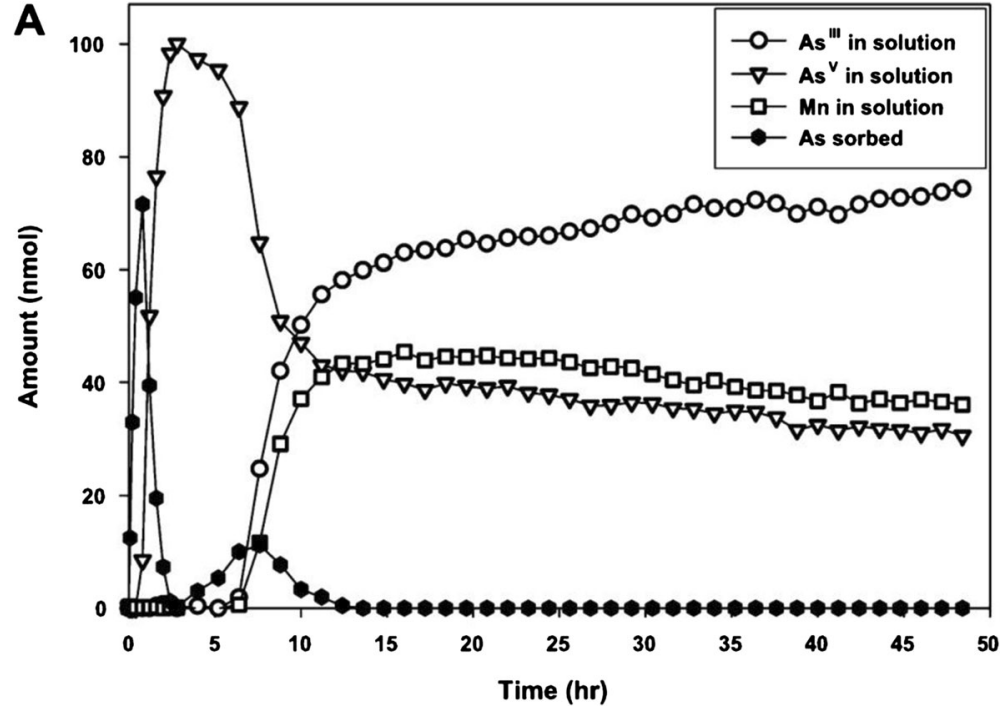


Fig. 8 Time 0 through 4 h As(V) is bound as bidentate-binuclear and monodenatemononuclear complexes. This is the time when $\mathrm{Mn}$ is primarily sorbing at vacancy sites. Time 10 through $48 \mathrm{~h} \mathrm{As}(\mathrm{V})$ is bound in bidentate-binuclear, monodenatemononuclear, and bidentatemononuclear. Bidentate-binuclear As-Mn length increases. Mn(III) is present when $\mathrm{As}(\mathrm{V})$ bonding changes. This is the time when Mn has filled all vacancy sites and begins to compete with As for edge sites. (From Lafferty et al. 2010b)
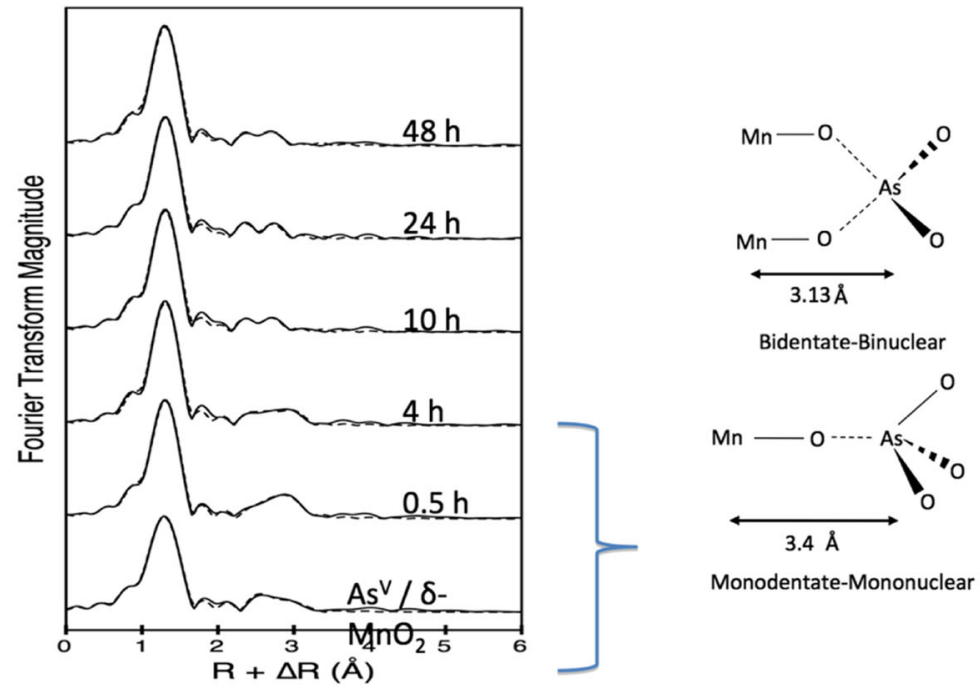

Monodentate-Mononuclear

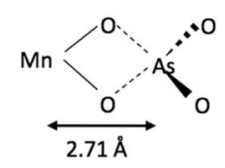

Bidentate-Mononuclear
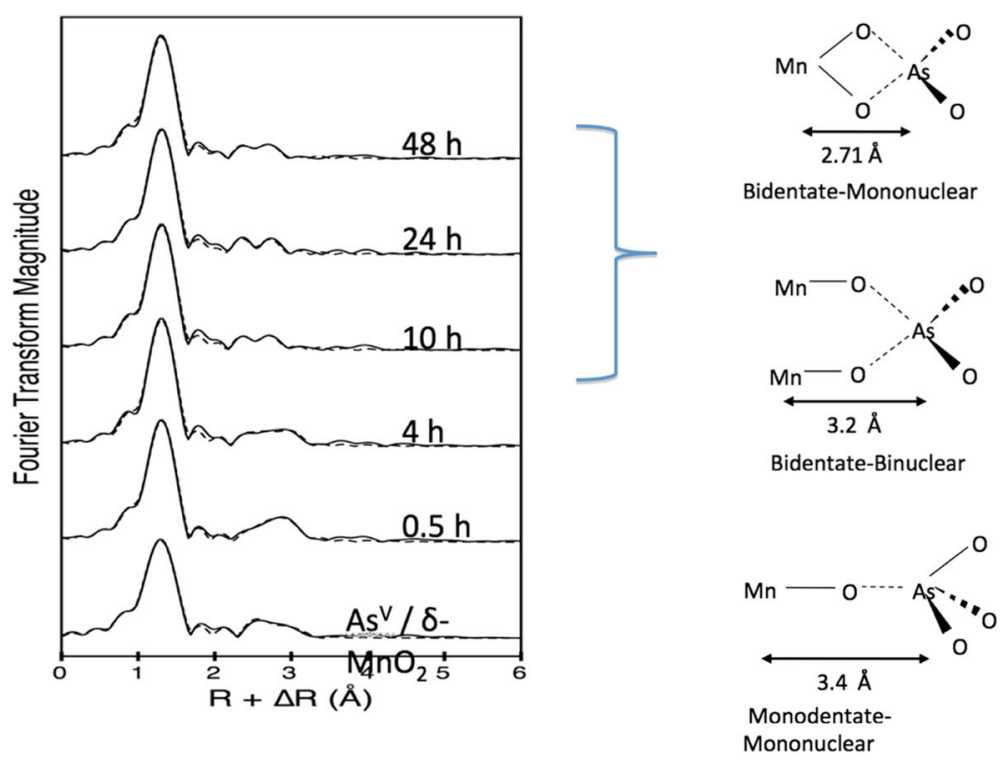

and $10 \mathrm{~h}$ the vacancy sites were filled and $\mathrm{Mn}$ (II) began to compete with $\mathrm{As}(\mathrm{V})$ for edge sites, causing a decrease in As(IIII) oxidation. Additionally, the data indicated that $\mathrm{Mn}$ (III) could be sorbing on edge sites via conproportionation. This results when $\mathrm{Mn}$ (II) is oxidized and $\mathrm{Mn}(\mathrm{IV})$ is reduced. Thus, passivation of the HMO surface was significantly affected not only by As(V) but most importantly, Mn(II) and Mn(III). As time proceeded, passivation of the surface was enhanced. XAS of As speciation showed that only As(V) species were present on the surface, but that the type of As(V) species changed as reaction time proceeded (Fig. 8). Up to $4 \mathrm{~h}$ of reaction time, the predominant inner-sphere adsorption complexes were bidentate binuclear and monodentate mononuclear but between 4 and $10 \mathrm{~h}$, when passivation ensued, there were two predominant species, bidentate binuclear and a bidentate mononuclear. A schematic showing the overall mechanism of As(III) oxidation on HMO is shown in Fig. 9. The data clearly show, once again, the importance of following reaction processes over time and at the molecular scale.

It had earlier been shown by Parikh et al. (2008) using single bounce, rapid scan attenuated total reflectance Fourier transform infrared (ATR-FTIR) spectroscopy, that As(III) oxidation on HMO was extremely rapid. To further understand the rapid kinetics, Ginder-Vogel 


\section{a 0 hours}

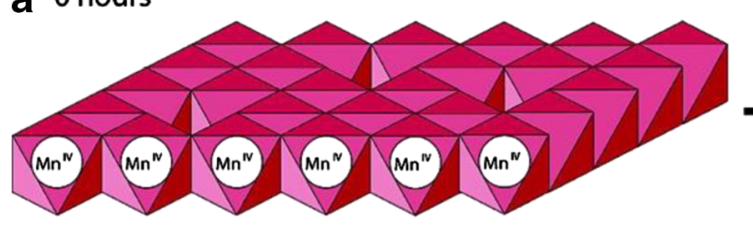

\section{b}
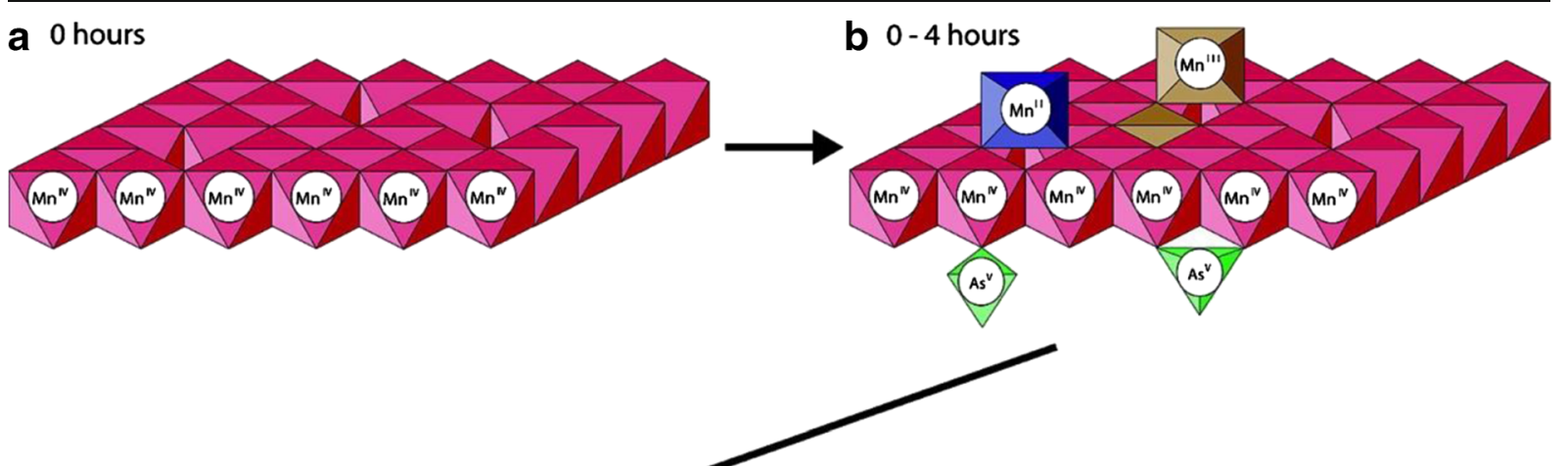

C $4-\sim 6$ hours

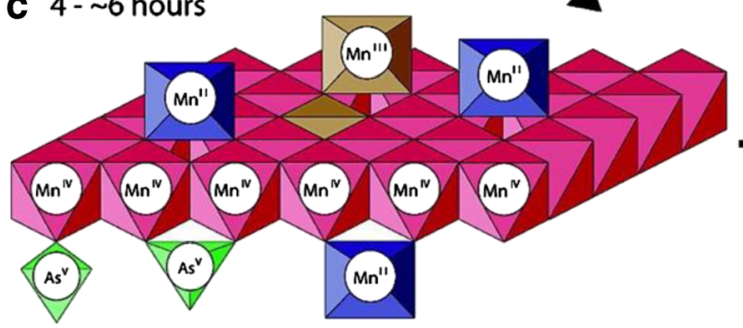

Fig. 9 Proposed reaction mechanism for As(III) oxidation by $\delta$ $\mathrm{MnO}_{2}$ over $48 \mathrm{~h}$ in a stirred-flow reactor. Throughout the reaction, $\mathrm{As}(\mathrm{III})$ is oxidized by $\mathrm{Mn}(\mathrm{IV})$ at $\delta-\mathrm{MnO}_{2}$ edge sites, producing $\mathrm{Mn}(\mathrm{II})$ and $\mathrm{As}(\mathrm{V})$. a Unreacted $\delta-\mathrm{MnO}_{2}$ octahedral layers consist of primarily $\mathrm{Mn}(\mathrm{IV})$ and have reaction sites at layer edges (edge sites) and vacancy sites. b During the first $4 \mathrm{~h}$ of As(III) oxidation, $\mathrm{Mn}(\mathrm{II})$ sorbs at $\delta-\mathrm{MnO}_{2}$ vacancy sites, and $\mathrm{As}(\mathrm{V})$ sorbs at edge sites in bidentate-binuclear and monodentate-mononuclear complexes. Also, a portion of sorbed $\mathrm{Mn}(\mathrm{II})$ reacts with $\mathrm{Mn}(\mathrm{IV})$ at vacancy sites to form $\mathrm{Mn}(\mathrm{III})$. c Between 4 and $6 \mathrm{~h}$ of reaction,

et al. (2009) employed a novel batch Q-XAS technique to study the rapid As(III) oxidation kinetics on HMO. A cam operated continuous scanning monochromator was employed (Fig. 1). The continuous rocking of the monochromator enabled one to obtain X-ray fluoresence spectra as the monochromator moved from low to high and high to low energies, greatly enhancing the time resolution. A complete XANES spectrum was collected in $980 \mathrm{~ms}$ (Fig. 10). In the study of Ginder-Vogel et al. (2009), the oxidation states in both the solution and at the mineral/water interface were probed using Q-XAS. The average oxidation state is then determined by fitting each individual XANES spectra with a linear combination of $\mathrm{As}(\mathrm{III})$ and $\mathrm{As}(\mathrm{V})$ standard solutions (in this experiment, $5 \mathrm{mM}$ standards were used). The fits provide the molar ratio of As in solution, from which the concentrations of $\mathrm{As}(\mathrm{III})$ and $\mathrm{As}(\mathrm{V})$ in the system can be calculated, using the initial As concentration. In Fig. 10 one sees the XANES spectra for the reaction of As(III) with HMO over time scales ranging from 0.98 to $298.9 \mathrm{sec}$.

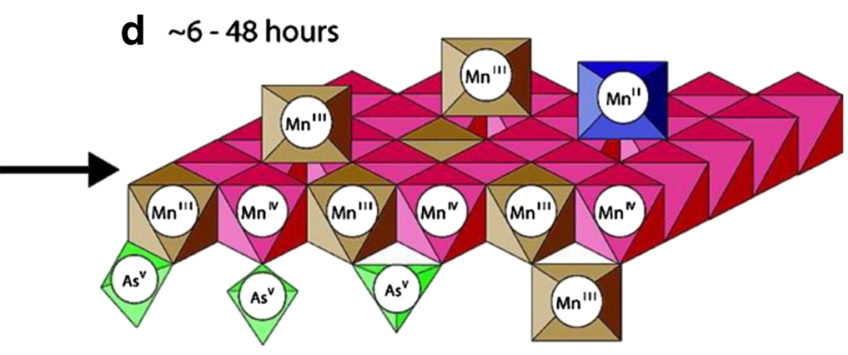

vacancy sites become filled with $\mathrm{Mn}$ (II/III), $\mathrm{Mn}$ (II) begins to sorb at $\delta-\mathrm{MnO}_{2}$ edge sites, and $\mathrm{As}(\mathrm{V})$ sorption continues in the same sorption complexes. $\mathbf{d}$ Beyond $6 \mathrm{~h}$ of reaction, $\mathrm{Mn}(\mathrm{II})$ at edge sites (and probably vacancy sites) reacts with $\mathrm{Mn}(\mathrm{III})$ in $\delta-\mathrm{MnO}_{2}$ octahedral layers to form $\mathrm{Mn}(\mathrm{III})$. The resulting $\mathrm{Mn}(\mathrm{III})$ changes the bonding environment of $\mathrm{As}(\mathrm{V})$, which begins to sorb in bidentate - mononuclear complexes, and the As-Mn distance in $\mathrm{As}(\mathrm{V})$ bidentate-binuclear complexes increases slightly. (Reprinted with permission from Lafferty et al. 2010b)

One sees the rapid transformation of $\mathrm{As}(\mathrm{III})$ to $\mathrm{As}(\mathrm{V})$ on the HMO surface. Complementary solution and surface concentrations for both Q-XAS and accompanying batch experiments show that after $1 \mathrm{sec}$, the $\mathrm{As}(\mathrm{V})$ concentration attains $0.37 \mathrm{mM}$ (Fig. 11) and increases precipitously for $45 \mathrm{sec}$ to reach a concentration of $1 \mathrm{mM}$, and then slowly reaches $1.5 \mathrm{mM}$ after $300 \mathrm{~s}$. Rate constants were determined from first-order plots for both the Q-XAS and batch experiments, based on biphasic kinetics (Table 2) and show, independent of method, that rate constants for As(III) depletion are about an order of magnitude larger during the initial portion of the reaction than in the later segment (Table 2). But, the initial rate constant of As(III) depletion, based on Q-XAS, was nearly twice as large $\left(4.7 \times 10^{-3} / \mathrm{sec}\right)$ as the rate constant measured with the batch method $\left(2.5 \times 10^{-3} / \mathrm{sec}\right.$, Table 2$)$.

Chromium predominantly exists in the environment in two oxidation states, Cr(III) or Cr(VI). Chromium(VI), chromate, is highly toxic to humans and is quite soluble and hence mobile under most 


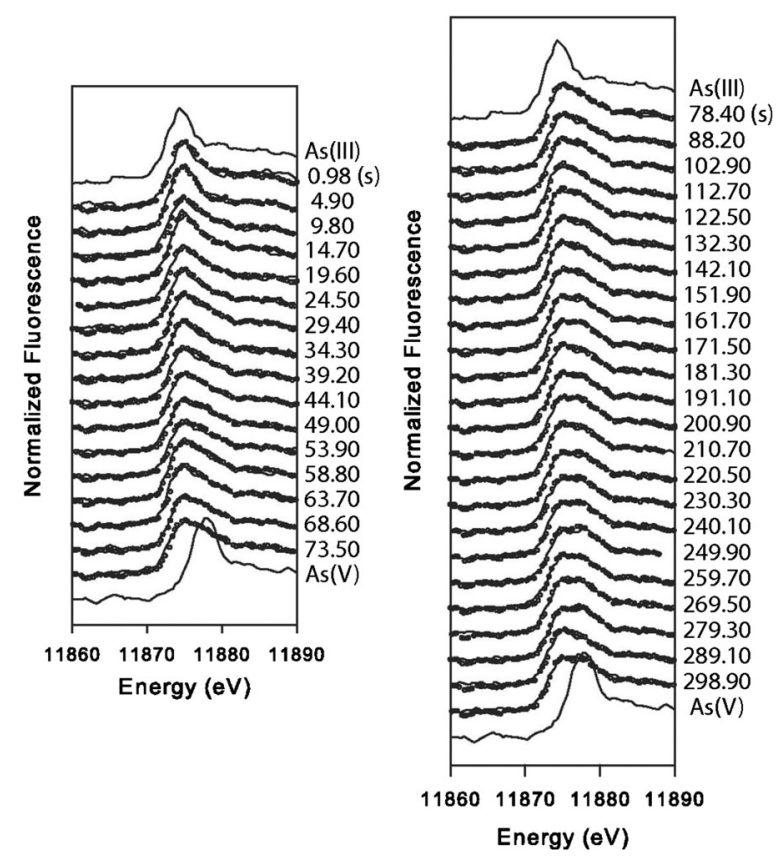

Fig. 10 Data (solid) and linear combination fits (dots) of individual As K-edge XANES spectra used to determine As(III) and $\mathrm{As}(\mathrm{V})$ concentrations during the batch reactions. Each spectrum was collected in approximately $980 \mathrm{~ms}$, with the time (in s) next to each spectrum indicating the time the last data point of each spectrum was collected. (Reprinted with permission from Ginder-Vogel et al. 2009)

common environmental conditions. Conversely, $\mathrm{Cr}$ (III) is less toxic and generally immobile. The identification and quantification of chromium oxidation states, using XANES spectroscopy, is quite straightforward, due to a prominent pre-edge peak at $5993 \mathrm{eV}$, when $\mathrm{Cr}$ is present as Cr(VI) (Peterson et al. 1996; Peterson et al. 1997), which is caused by a bound-state $1 \mathrm{~s}$ to $3 \mathrm{~d}$ transition.

Landrot et al. (2010) employed the same technique as Ginder-Vogel et al. (2009) to measure the rapid, initial kinetics of $\mathrm{Cr}$ (III) oxidation on HMO. A complete XANES spectrum was determined in 0.75 sec. Data were collected at $\mathrm{pHs}$ of $2.5,3.0$ and 3.5 at $\mathrm{Cr}$ (III) concentrations of $40-100 \mathrm{mM}$. Chromium (VI), resulting from the oxidation of $\mathrm{Cr}$ (III) on the HMO surface, displays the prominent pre-edge feature in the XAS spectrum, which is related to the proportion of $\mathrm{Cr}(\mathrm{VI})$ in the system. Therefore, one only needs to measure the height of the pre-edge feature and compare it to a set of $\mathrm{Cr}(\mathrm{III}) / \mathrm{Cr}(\mathrm{VI})$ mixtures to determine the amount of $\mathrm{Cr}(\mathrm{VI})$ present in the system (Peterson et al. 1997; Landrot et al. 2010). One sees in Fig. 12 that the pre-edge feature increases in intensity with time, indicating the oxidation of $\mathrm{Cr}(\mathrm{III})$ to $\mathrm{Cr}(\mathrm{VI})$. Chromium (III) oxidation is quite rapid during the first $120 \mathrm{sec}$ of the reaction, when about $35 \mathrm{mM}$ of chromate was produced. Initial reaction rates were determined by quantifying the $\mathrm{Cr}(\mathrm{VI})$ from the preedge feature height for each experiment during a time range of $0-1 \mathrm{~min}$ of the reaction. Landrot et al. (2010) found at a given $\mathrm{pH}$ and for varying $\mathrm{Cr}$ (III) and HMO concentrations that the rate constants were similar. This strongly suggests that the $\mathrm{k}$ values are chemical rate constants since only temperature should impact the magnitude of the $\mathrm{k}$ values. Therefore, the use of a method like Q-XAS not only provides valuable information on rapid, initial reaction processes, but an additional benefit is that one can determine chemical kinetics rate constants. Together, these provide important insights on reaction mechanisms. Using most other techniques, one cannot significantly reduce or eliminate transport processes. Consequently, the rate parameters that are measured are apparent rate coefficients, and not rate constants (Sparks 1989, 2002).

\section{Light element speciation mechanisms}

Over the past decades, solid-phase speciation studies of $\mathrm{P}$ have relied largely on the use of spectroscopic techniques, especially Fourier transform infra-red (FTIR) (Tejedor-Tejedor and Anderson, 1990; Persson et al. 1996; Arai and Sparks 2001; Elzinga and Sparks 2007; Luengo et al. 2006; Antelo et al. 2010), ${ }^{31} \mathrm{P}$ solid-state NMR (Bleam et al. 1991; Kim and Kirkpatrick 2004; Li et al. 2010, 2013a, b; Kim et al. 2011) and synchrotronbased X-ray pair distribution function (PDF) analyses (Wang et al. 2013).

The use of XAS to study light element chemistry of $\mathrm{P}$ and $\mathrm{S}$ reactivity with minerals, soils, and agricultural byproducts has been limited (Hesterberg et al. 1999; Peak et al. 2002; Khare et al. 2005; Khare et al. 2007; Negassa et al. 2010; Lombi et al. 2011; Solomon et al. 2011; Blum et al. 2013; Zhu et al. 2014). This is due to several reasons: low binding energy of the $1 \mathrm{~s}$ orbital; sampling depth in adsorption samples is only a few microns, and transmission measurements are not possible; weak scattering ability; low fluorescence efficiency; data analyses is difficult especially because of multiple scattering; and there is a lack of good XAS fitting software. Despite these challenges, progress is being made at several beamlines. At the National 
Fig. $11 \mathrm{As}(\mathrm{V})$ and $\mathrm{As}(\mathrm{III})$ concentrations determined from traditional batch and Q-XAS reactions. Error bars represent the $\mathrm{SD}$ of 3 measurements made at each time point. XANES spectra and fits used to calculate Q-XAS As concentrations are shown in Fig. 10. (Reprinted with permission from Ginder-Vogel et al. 2009)

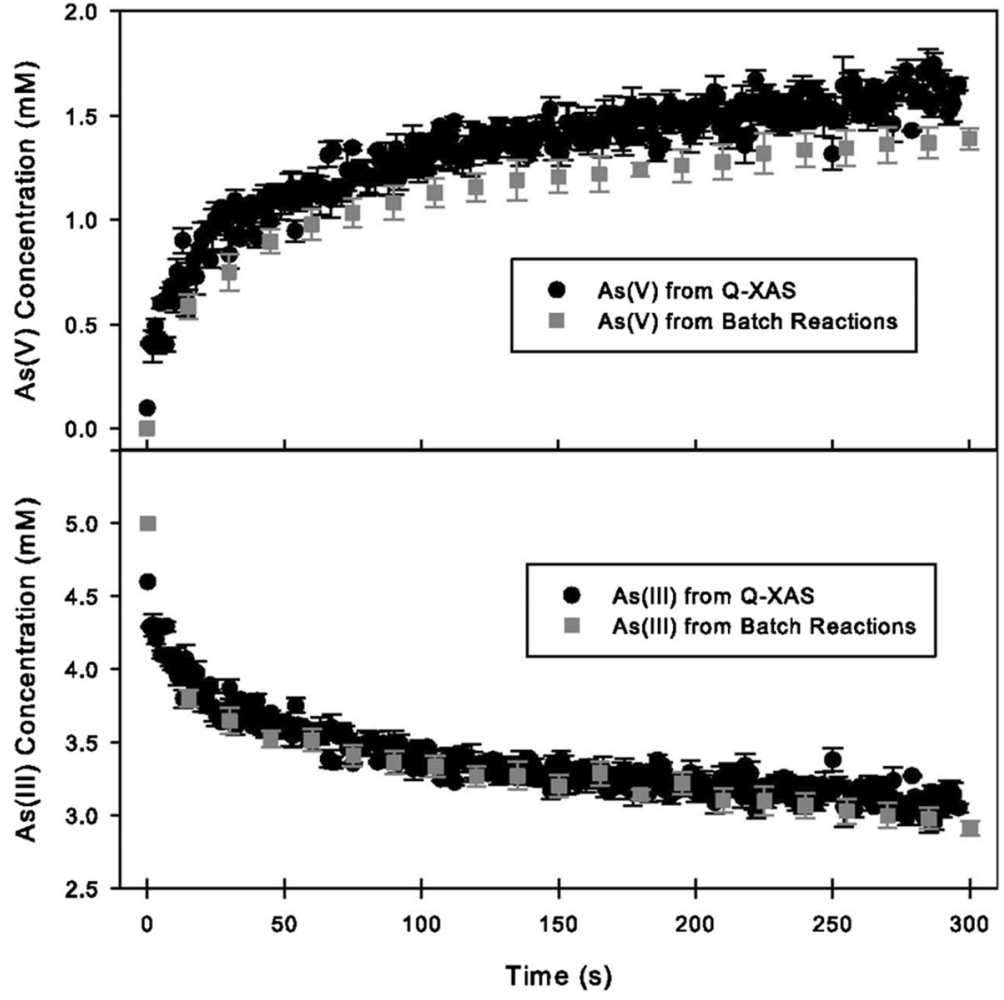

Synchrotron Light Source (NSLS) at Brookhaven National Laboratory, one will soon be able to employ both bulk XAS as well as micro-focused XRF to study heterogeneous samples such as soils. This will provide useful information on direct speciation of $\mathrm{P}$.

Much controversy has appeared in the scientific literature on the bonding mechanism(s) of sulfate on mineral surfaces. Much of the research has been reported based on the use of infrared spectroscopy. These studies have indicated that sulfate can form both inner-sphere and outer-sphere complexes and that the relative proportion depends on environmental factors such as $\mathrm{pH}$, ionic strength, surface coverage, and hydration (Zhu et al. 2014). Uncertainty also existes on what type of inner-sphere complex exists, i.e., monodentate-mononuclear versus bidentate-binuclear, due to problems in interpreting the IR spectra (Zhu et al. 2014). Zhu et al. (2014) determined the bonding mechanisms of adsorbed sulfate on ferrihydrite using S K-edge extended X-ray absorption fine structure spectroscopy and differential X-ray pair distribution function analysis (d-PDF). There was good agreement between the two approaches in determining the bond

Table 2 Apparent, first-order rate constants determined from batch and Q-XAS experiments

\begin{tabular}{|c|c|c|c|c|}
\hline Experiment type & Time period (s) & No. of data points & $k\left(\mathrm{~s}^{-1}\right)$ & $r^{2}$ \\
\hline As(III)-Batch & $1-60$ & 4 & $2.5(3) \times 10^{-3}$ & 0.96 \\
\hline As(III)-Batch & $135-300$ & 14 & $6.1(4) \times 10^{-4}$ & 0.82 \\
\hline As(III)-Q-XAS & $1-30$ & 30 & $4.7(4) \times 10^{-3}$ & 0.91 \\
\hline As(III)-Q-XAS & $135-300$ & 168 & $4.9(4) \times 10^{-4}$ & 0.74 \\
\hline
\end{tabular}

The rate constants of As(III) depletion were determined by linear regression analysis of the noted time-periods. (Reprinted by permission from Landrot et al. 2010 
Fig. $12 \mathrm{Cr}$ (III) oxidation kinetics using a Q-XAFS technique, at $\mathrm{pH} 2.5,[\mathrm{Cr}(\mathrm{III})]=100 \mathrm{mM}$, $[\mathrm{HMO}]=20 \mathrm{~g} / \mathrm{L}$, and $0-240 \mathrm{~s}$. Each XANES spectrum shown represents $3 \mathrm{~s}$ of the reaction (average of four $0.75 \mathrm{~s}$ spectra). (Reprinted with permission from Landrot et al. 2010)

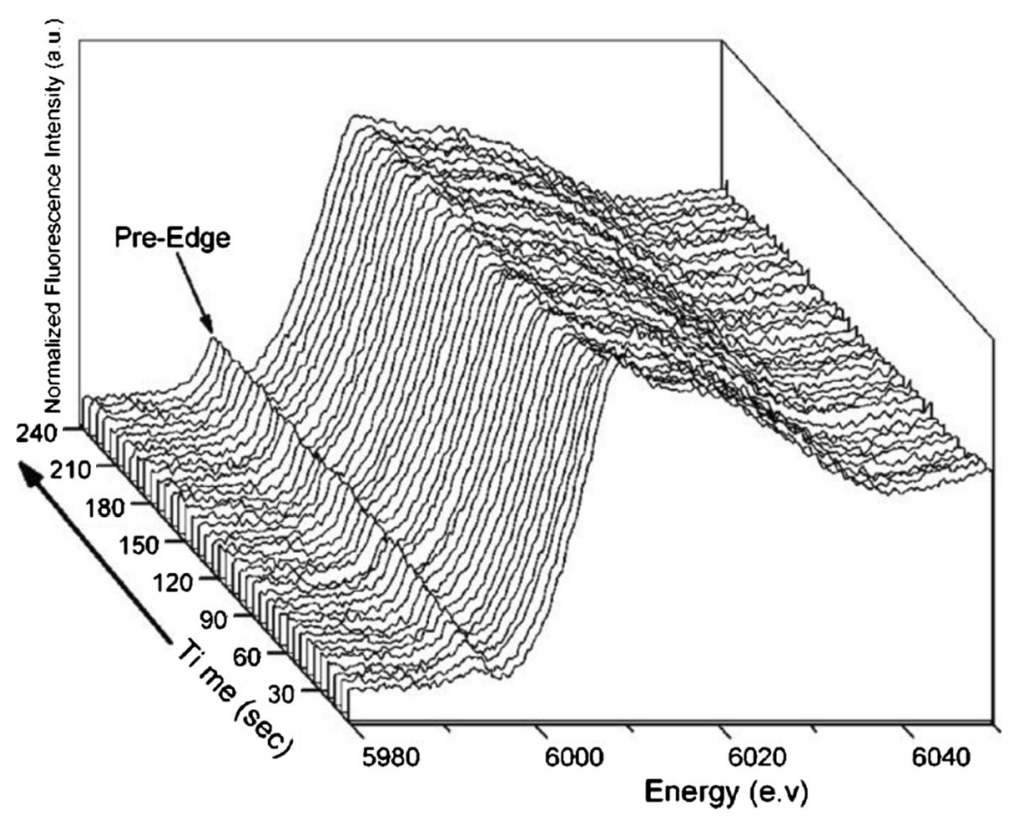

distances between S-O, representing the first shell and S-Fe, representing the second shell (Table 3).
Both approaches showed that the S-Fe interatomic distance of the sulfate adsorption complexes was

Table 3 Structural Parameters of Sulfate Adsorbed on Ferrihydrite and Reference Samples Determined by EXAFS and d-PDF Analyses ${ }^{\mathrm{a}}$

\begin{tabular}{|c|c|c|c|c|c|c|c|c|c|}
\hline & \multicolumn{9}{|c|}{ EXAFS spectroscopy } \\
\hline & $\mathrm{S}-\mathrm{O}$ & & & $\mathrm{S}-\mathrm{Fe}$ & & & & & \\
\hline & $\mathrm{d}(\AA)$ & $\mathrm{CN}$ & $\sigma^{2}\left(\AA^{2}\right)$ & $\mathrm{d}(\AA)$ & $\mathrm{CN}$ & $\sigma^{2}\left(\AA^{2}\right)$ & $\Delta \mathrm{E}$ & $\mathrm{R}$ & Red- $-\chi^{2}$ \\
\hline${ }^{\mathrm{a}}$ Solution & $1.48(0.01)$ & ${ }^{\mathrm{c}} 4$ & $0.0003(0.001)$ & - & - & - & $7.4(3.1)$ & 0.0267 & 31.7 \\
\hline Jarosite & $1.46(0.01)$ & ${ }^{\mathrm{c}} 4$ & $<0.0001$ & $3.20(0.03)$ & ${ }^{c} 3$ & $0.006(0.003)$ & $2.5(2.7)$ & 0.0323 & 76.6 \\
\hline bJarosite (XRD) & ${ }^{b} 1.48(0.01)$ & 4 & - & $\mathrm{b}_{3.23(0.01)}$ & 3 & - & - & - & - \\
\hline $\mathrm{S} 1$ & $1.47(0.01)$ & $4.1(0.9)$ & $<0.0001$ & $3.19(0.06)$ & $1.2(2.9)$ & $0.002(0.015)$ & $3.2(5.1)$ & 0.0583 & 106.6 \\
\hline $\mathrm{S} 2$ & $1.46(0.01)$ & $4.1(0.7)$ & $<0.0001$ & $3.18(0.05)$ & $1.6(3.2)$ & $0.005(0.01)$ & $3(4)$ & 0.0261 & 97.4 \\
\hline \multirow[t]{4}{*}{ S3 } & $1.46(0.01)$ & $4.1(0.7)$ & $0.0003(0.001)$ & $3.19(0.05)$ & $1.3(2.4)$ & $0.004(0.01)$ & $3.0(3.8)$ & 0.0239 & 91.02 \\
\hline & \multicolumn{9}{|c|}{ d-PDF analysis } \\
\hline & $\mathrm{S}-\mathrm{O}$ & & & & $\mathrm{S}-\mathrm{Fe}$ & & & & \\
\hline & $\mathrm{d}(\AA)$ & & $\mathrm{CN}$ & & $\mathrm{d}(\AA)$ & & & $\mathrm{CN}$ & \\
\hline $\mathrm{S} 1$ & 1.47 & & 4 & & 3.25 & & & 1.56 & \\
\hline $\mathrm{S} 2$ & 1.46 & & 4 & & 3.24 & & & 1.58 & \\
\hline $\mathrm{S} 3$ & 1.47 & & 4 & & 3.27 & & & 2.02 & \\
\hline Average & $1.47(0.01)$ & & 4 & & $3.25(0.02)$ & & & $1.7(0.3)$ & \\
\hline${ }^{\mathrm{a}}$ Solution & 1.48 & & 4 & & - & & & - & \\
\hline
\end{tabular}

${ }^{\mathrm{a}} 0.5 \mathrm{M}$ sodium sulfate solution at $\mathrm{pH} 4$

$\mathrm{b}$ averaged XRD-determined structural parameters of jarosites published in literature [34-37]

${ }^{\mathrm{c}}$ fixed during the fitting

(Reprinted with permission from Zhu et al. 2014) 

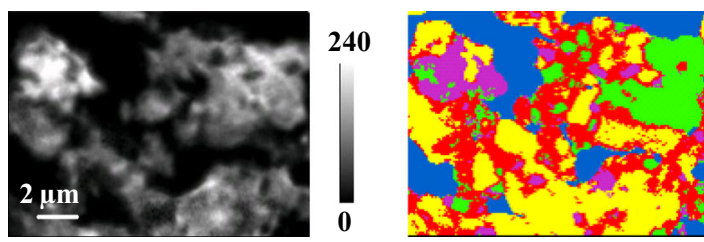

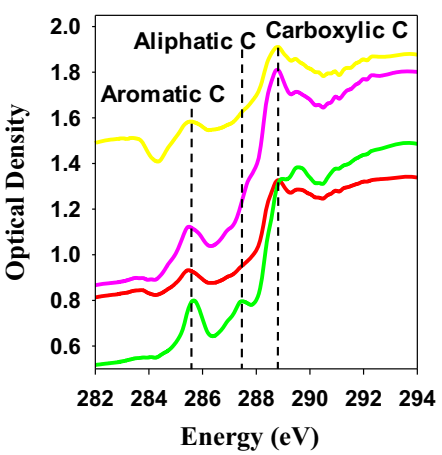

Source). The gray scale indicates thickness in nanometers. Blue region indicates no $\mathrm{C}$ is present while other colors show different regions of C . From (Chen et al. 2014, unpublished data)

transmission X-ray microscopy (STXM) to speciate carbon in soils and better understand mechanisms of sequestration and association with other elements (Lehmann et al. 2005; Schumacher et al. 2005; Solomon et al. 2005; Lombi et al. 2006; Wan et al. 2007; Liang et al. 2008; Lehmann et al. 2008; Solomon et al. 2009).

One significant mechanism for $\mathrm{C}$ sequestration in soils is its complexation with soil minerals, e.g., clay minerals and metal hydr(oxides), especially Fe-hydr(oxides). There is not space to review the large amount of good research that has been conducted in this area. Accordingly, I will present some recent data from my own research group to illustrate the use of synchrotronbased techniques, to glean insights into $\mathrm{C}$ complexation in soils.

Chen et al. (2014), using synchrotron-based carbon near edge X-ray absorption fine structure spectroscopy (C-NEXAFS) and scanning transmission X-ray microscopy (STXM), studied C speciation and elemental associations in the clay fraction of a pasture soil from the Christina River Basin Critical Zone Observatory (CRBCZO). Using STXM, coupled with C-NEXAS, several $\mathrm{C}$ regions were located (colors) and for each region, major functional groups could be determined (Fig. 13).
Fig. 14 Submicron- and nanoscale correlation of interested elements $(\mathrm{C}, \mathrm{Ca}, \mathrm{Fe}, \mathrm{Al}$ and $\mathrm{Si})$ in the clay fraction of a soil using STXM coupled C K-edge NEXAFS spectroscopy (From Chen et al. 2014, unpublished data)
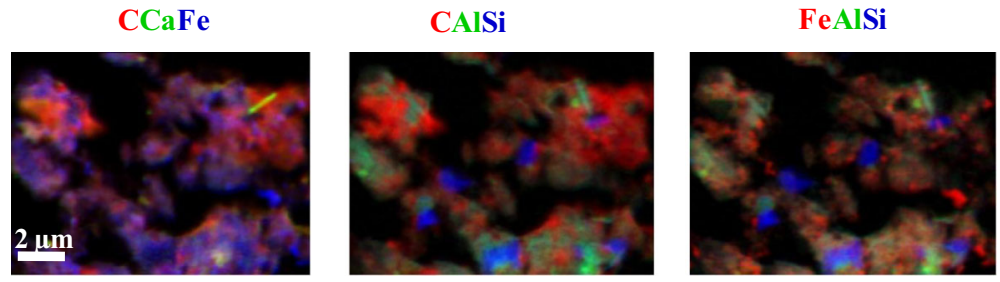
STXM analyses (Fig. 14) showed that: Fe was strongly correlated to $\mathrm{Al}$, which could be related to coating of Feoxides on clay minerals and structural $\mathrm{Fe}$ in clays; $\mathrm{C}$ and $\mathrm{Ca}$ were strongly correlated, which could be due to sorption of $\mathrm{Ca}$ on negatively charged functional groups of SOM and perhaps to cation bridging. No inorganic $\mathrm{C}$ was found in the soil. It is also clear from the STXM images and the correlation analyses that $\mathrm{C}$ and $\mathrm{Fe}$ are very closely correlated whereas there is poor correlation between $\mathrm{C}$ and $\mathrm{Si}$, not surprising since the $\mathrm{Si}$ is related to quartz content. Quartz is expected to have very low reactivity with $\mathrm{C}$.

\section{Future research needs}

Advances have been made in the study of biogeochemical processes in soils, such as sorption, precipitation, and redox using both kinetic and molecular scale techniques. A greater understanding of these processes is critical if we are going to address major societal challenges facing humankind including soil contamination, food security, and climate change. There is a pressing need to conduct more studies where kinetic processes are coupled with molecular scale investigations in realtime and in-situ. Such research, some of which has been presented here, will advance our understanding of the dynamics and mechanisms of reactions in heterogeneous soils. This information is vital to predict the fate and transport of metal(loids) and nutrients in soils. Of particular need is an enhanced understanding of light element biogeochemical processes.

\section{References}

Antelo J, Fiol S, Perez C, Marino S, Arce F, Gondar D, Lopez R (2010) Analysis of phosphate adsorption onto ferrihydrite using the CD-MUSIC model. J Colloid Interface Sci 347: 112-119

Arai Y, Sparks DL (2001) ATR-FTIR spectroscopic investigation on phosphate adsorption mechanisms at the ferrihydritewater interface. J Colloid Interface Sci 241:317-326

Bertsch PM, Hunter DB (1998) Elucidating fundamental mechanisms in soil and environmental chemistry: the role of advanced analytical, spectroscopic, and microscopic methods. In: Huang PM (ed) Future prospects for soil chemistry. Soil Science Society America, Madison

Bertsch PM, Hunter DB (2001) Applications of synchrotron based X-ray microprobes. Chem Rev 101:1809-1842

Bleam WF, Pfeffer PE, Goldberg S, Taylor RW, Dudley R (1991) A P-31 solid-state nuclear-magnetic-resonance study of phosphate adsorption at the boehmite aqueous-solution interface. Langmuir 7:1702-1712

Blum SC, Lehmann J, Solomon D, Caires EF, Alleoni LRF (2013) Sulfur forms in organic substrates affecting S mineralization in soil. Geoderma 200:156-164

Borda MJ, Sparks DL (2008) Kinetics and mechanisms of sorption-desorption in soils: a multiscale assessment. In: Violante A, Huang PM, Gadd GM (eds) Biophysico-chemical processes of heavy metals and metalloids in soil environments. Wiley, New York

Brown GE Jr (1990) Spectroscopic studies of chemisorption reaction mechanisms at oxide-water interfaces. In: White AF, Hochella MF (eds) Mineral-water interface geochemistry. Mineralogical Society of America, Washington

Brown GE Jr, Sturchio NC (2002) An overview of synchrotron radiation applications to low temperature geochemistry and environmental science. In: Fenter PA, Rivers ML, Sturchio NC, Sutton SR (eds) Applications of synchrotron radiation in Low-temperature geochemistry and environmental sciences. Geochemical Society, Mineralogical Society of America, Washington

Brown GE, Parks GA (2001) Sorption of trace elements on mineral surfaces: Modern perspectives from spectroscopic studies, and comments on sorption in the marine environment. International Geology Review 43: 963-1073

Chen C, Dynes JJ, Wang J, Karunakaran C, Sparks DL (2014) Soft $\mathrm{X}$-ray spectromicroscopy study of mineral-organic matter associations in pasture soil clay fractions Environ Sci Technol (In review).

Dent AJ (2002) Development of time-resolved XAFS instrumentation for quick EXAFS and energy-dispersive EXAFS measurements on catalyst systems. Top Catal 18:27-35

Elzinga EJ, Sparks DL (1999) Nickel sorption mechanisms in a pyrophyllite-montmorillonite mixture. J Colloid Interface Sci 213:506-512

Elzinga EJ, Sparks DL (2001) Reaction condition effects on nickel sorption mechanisms in illite-water suspensions. Soil Sci Soc Am J 65:94-101

Elzinga EJ, Sparks DL (2007) Phosphate adsorption onto hematite: an in situ ATR-FTIR investigation of the effects of $\mathrm{pH}$ and loading level on the mode of phosphate surface complexation. J Colloid Interface Sci 308:53-70

Fendorf SE, Sparks DL, Franz JA, Camaioni DM (1993) Electron paramagnetic resonance stopped-flow kinetic study of manganese (II) sorption-desorption on birnessite. Soil Sci Soc Am J 57:57-62

Fendorf SE, Lamble GM, Stapleton MG, Kelley MJ, Sparks DL (1994) Mechanisms of chromium (III) sorption on silica: 1. Cr(III) surface structure derived by extended $\mathrm{x}$-ray absorption fine structure spectroscopy. Environ Sci Technol 28:284-289

Fenter PA, Rivers ML, Sturchio NC, Sutton SR (eds) (2002) Applications of synchroton radiation in low-temperature geochemistry and environmental sciences. Geochemical Society. Mineralogical Society of America, Washington

Ford RG, Sparks DL (2000) The nature of $\mathrm{Zn}$ precipitates formed in the presence of pyrophyllite. Environ Sci Technol 34: 2479-2483

Ford RG, Scheinost AC, Scheckel KG, Sparks DL (1999) The link between clay mineral weathering and the 
stabilization of Ni surface precipitates. Environ Sci Technol 33:3140-3144

Ginder-Vogel M, Sparks DL (2010) The impacts of X-ray absorption spectroscopy on understanding soil processes and reaction mechanisms. In: Balwant S, Markus G (eds) Developments in Soil Science. Elsevier, New York

Ginder-Vogel M, Landrot G, Fischel JS, Sparks DL (2009) Quantification of rapid environmental redox processes with quick-scanning x-ray absorption spectroscopy (Q-XAS). Proc Natl Acad Sci U S A 106:16124-16128

Grafe M, Donner E, Collins RN, Lombi E (2014) Speciation of metal(loid)s in environmental samples by X-ray absorption spectroscopy: A critical review. Anal Chim Acta 822: 1-22

Hayes KF, Roe AL, Brown GE Jr, Hodgson KO, Leckie JO, Parks GA (1987) In situ x-ray absorption study of surface complexes: Selenium oxyanions on $\alpha$-FeOOH. Science 238:783-786

Hesterberg D, Zhou WQ, Hutchison KJ, Beauchemin S, Sayers DE (1999) XAFS study of adsorbed and mineral forms of phosphate. J Synchrotron Radiat 6:636-638

Hug SJ (1997) In situ Fourier-transform infrared measurements of sulfate adsorption on hematite in aqueous solutions. J Colloid Interface Sci 188:415-422

Hunter DB, Bertsch PM (1998) In situ examination of uranium contaminated soil particles by micro-X-ray absorption and micro-fluorescence spectroscopies. J Radioanal Nucl Chem 234:237-242

Juillot F, Morin G, Ildefonse P, Trainor TP, Benedetti M, Galoisy L, Calas G, Brown GE (2003) Occurrence of Zn/Al hydrotalcite in smelter-impacted soils from northern France: evidence from EXAFS spectroscopy and chemical extractions. Am Mineral 88:509-526

Kelly SD, Hesterberg D, Ravel B (2008) Analysis of soils and minerals using X-ray absorption spectroscopy. In: Ulery AL, Drees LR (eds) Methods of soil analysis part 5 mineralogical methods. Soil Science Society of America, Madison

Khalid S, Caliebe W, Siddons P, So I, Clay B, Lenhard T, Hanson J, Wang Q, Frenkel AI, Marinkovic N, Hould N, GinderVogel M, Landrot GL, Sparks DL, Ganjoo A (2010) Quick extended $\mathrm{x}$-ray absorption fine structure instrument with millisecond time scale, optimized for in situ applications. Rev Sci Instrum 81: 015105-015107

Khaokaew S, Landrot G, Chaney RL, Pandya K, Sparks DL (2012) Speciation and release kinetics of zinc in contaminated paddy soils. Environ Sci Technol 46: 3957-3963

Khare N, Hesterberg D, Martin JD (2005) XANES investigation of phosphate sorption in single and binary systems of iron and aluminum oxide minerals. Environ Sci Technol 39: 2152-2160

Khare N, Martin JD, Hesterberg D (2007) Phosphate bonding configuration on ferrihydrite based on molecular orbital calculations and XANES fingerprinting. Geochim Cosmochim Acta 71:4405-4415

Kim Y, Kirkpatrick RJ (2004) An investigation of phosphate adsorbed on aluminium oxyhydroxide and oxide phases by nuclear magnetic resonance. Eur J Soil Sci 55:243-251

Kim J, Li W, Philips BL, Grey CP (2011) Phosphate adsorption on the iron oxyhydroxides goethite $(\mathrm{a}-\mathrm{FeOOH})$, akaganeite $(\beta$ $\mathrm{FeOOH})$, and lepidocrocite $(\gamma-\mathrm{FeOOH}): \mathrm{A}{ }^{31} \mathrm{P}$ NMR study. Energy Environ Sci 4:4298-4305
Lafferty BJ, Ginder-Vogel M, Sparks DL (2010a) Arsenite oxidation by a poorly crystalline manganese-oxide 1 . Stirred-flow experiments. Environ Sci Technol 44:8460-8466

Lafferty BJ, Ginder-Vogel M, Zhu M, Livi KJT, Sparks DL (2010b) Arsenite oxidation by a poorly crystalline manganese-oxide. 2. Results from x-ray absorption spectroscopy and x-ray diffraction. Environ Sci Technol 44:8467-8472

Lafferty BJ, Ginder-Vogel M, Sparks DL (2011) Arsenite oxidation by a poorly-crystalline manganese oxide. 3. Arsenic and manganese desorption. Environ Sci Technol 45:9218-9223

Landrot G, Ginder-Vogel M, Sparks DL (2010) Kinetics of chromium(III) oxidation by manganese(IV) oxides using quick scanning X-ray absorption fine structure spectroscopy (Q-XAFS). Environ Sci Technol 44:143-149

Lehmann J, Liang BQ, Solomon D, Lerotic M, Luizao F, Kinyangi J, Schafer T, Wirick S, Jacobsen C (2005) Near-edge X-ray absorption fine structure (NEXAFS) spectroscopy for mapping nano-scale distribution of organic carbon forms in soil: Application to black carbon particles. Glob Biogeochem Cycles 19:GB1013

Lehmann J, Solomon D, Kinyangi J, Dathe L, Wirick S, Jacobsen C (2008) Spatial complexity of soil organic matter forms at nanometre scales. Nat Geosci 1:238-242

Li W, Feng J, Kwon KD, Kubicki JD, Phillips BL (2010) Surface speciation of phosphate on bohemite $(\gamma-\mathrm{AlOOH})$ determined from NMR spectrsocoy. Langmuir 26:4753-4761

Li W, Livi KJT, Xu W, Siebecker MG, Wang Y, Phillips BL, Sparks DL (2012) Formation of crystalline Zn-Al layered double hydroxide precipitates on $\gamma$-alumina: the role of mineral dissolution. Environ Sci Technol 46:11670-11677

Li W, Pierre-Louis AM, Kwon KD, Kubicki JD, Strongin DR, Phillips BL (2013a) Molecular level investigations of phosphate sorption on the corundum $(\alpha-\mathrm{A} 12 \mathrm{O} 3)$ surface by ${ }^{31} \mathrm{P}$ solid state NMR, ATR-FTIR and quantum chemical calculations. Geochim Cosmochim Acta 107:252-266

Li W, Feng X, Yan Y, Sparks DL, Phillips BL (2013b) Solid state NMR spectroscopic study of phosphate sorption mechanisms on aluminum (hydr)oxides. Environ Sci Technol 47:8308-8315

Liang B, Lehmann J, Solomon D, Sohi S, Thies JE, Skjemstad JO, Luizao FJ, Engelhard MH, Neves EG, Wirick S (2008) Stability of biomass-derived black carbon in soils. Geochim Cosmochim Acta 72:6069-6078

Livi KJT, Senesi GS, Scheinost AC, Sparks DL (2009) Microscopic examination of nanosized mixed Ni-Al hydroxide surface precipitates on pyrophyllite. Environ Sci Technol 43:1299-1304

Lombi E, Susini J (2009) Synchrotron-based techniques for plant and soil science: opportunities, challenges and future perspectives. Plant Soil 320:1-35

Lombi E, Scheckel KG, Armstrong RD, Forrester S, Cutler JN, Paterson D (2006) Speciation and distribution of phosphorus in a fertilized soil: a synchrotron-based investigation. Soil Sci Soc Am J 70:2038-2048

Lombi E, Hettiarachchi GM, Scheckel KG (2011) Advanced in situ spectroscopic techniques and their applications in environmental biogeochemistry: introduction to the special section. J Environ Qual 40:659-666

Luengo C, Brigante M, Antelo J, Avena M (2006) Kinetics of phosphate adsorption on goethite: comparing batch adsorption and ATR-IR measurements. J Colloid Interface Sci 300: 511-518 
Manceau A, Charlet L (1994) The mechanism of selenate adsorption on goethite and hydrous ferric oxide. J Colloid Interface Sci 164:87-93

Manceau A, Charlet L, Boisset MC, Didier B, Spadini L (1992) Sorption and speciation of heavy metals on hydrous Fe and Mn oxides. from microscopic to macroscopic. Appl Clay Sci 7:201-223

Manceau A, Lanson B, Schlegel ML, Harge JC, Musso M, Eybert-Berard L, Hazemann JL, Chateigner D, Lamble GM (2000) Quantitative Zn speciation in smeltercontaminated soils by EXAFS spectroscopy. Am J Sci 300:289-343

Manceau A, Marcus MA, Tamura N (2002) Quantitative speciation of heavy metals in soils and sediments by synchrotron Xray techniques. In: Fenter P, Sturchio NC (eds) Applications of synchrotron radiation in Low-temperature geochemistry and environmental science. Mineralogical Society of America, Washingon

McBride MB (1994) Environmental chemistry of soils. Oxford University Press, New York

McNear DH, Chaney RL, Sparks DL (2007) The effects of soil type and chemical treatment on nickel speciation in refinery enriched soils: a multi-technique investigation. Geochim Cosmochim Acta 71:2190-2208

Mitsunobu S, Harada T, Takahashi Y (2006) Comparison of antimony behavior with that of arsenic under various soil redox conditions. Environ Sci Technol 40: 72707276

Nachtegaal M, Marcus MA, Sonke JE, Vangronsveld J, Livi KJT, Van der Lelie D, Sparks DL (2005) Effects of in situ remediation on the speciation and bioavailability of zinc in a smelter contaminated soil. Geochim Cosmochim Acta 69: 4649-4664

Negassa W, Kruse J, Michalik D, Appathurai N, Zuin L, Leinweber P (2010) Phosphorus speciation in agroindustrial byproducts: sequential fractionation, solution P31 NMR, and P K- and L-2, L-3-edge XANES spectroscopy. Environ Sci Technol 44:2092-2097

O'Day PA (1999) Molecular environmental geochemistry. Rev Geophys 37:249-274

Parikh SJ, Lafferty BJ, Sparks DL (2008) An ATR-FTIR spectroscopic approach for measuring rapid kinetics at the mineral/water interface. J Colloid Interface Sci 320: $177-185$

Parikh SJ, Margenot AJ, Mukome FND, Calderon F, Goyne KW (2014) Soil chemical insights provided through vibrational spectroscopy. In: Sparks DL (ed) Advances in agronomy, vol 126. Academic Press, San Diego

Peak D, Ford RG, Sparks DL (1999) An in-situ ATR-FTIR investigation of sulfate bonding mechanisms on goethite. J Colloid Interface Sci 218:289-299

Peak D, Sims JT, Sparks DL (2002) Solid-state speciation of natural and alum-amended poultry litter using XANES spectroscopy. Environ Sci Technol 36:42534261

Peltier E, Allada R, Navrotsky A, Sparks DL (2006) Nickel solubility and precipitation in soils: a thermodynamic study. Clay Clay Miner 54:153-164

Peltier E, van der Lelie D, Sparks DL (2009) Formation and stability of $\mathrm{Ni}-\mathrm{Al}$ hydroxide phases in soils. Environ Sci Technol 44:302-308
Persson P, Nilsson N, Sjoberg S (1996) Structure and bonding of orthophosphate ions at the iron oxide-aqueous interface. J Colloid Interface Sci 177:263-275

Peterson ML, Brown GE Jr, Parks GA (1996) Direct XAFS evidence for heterogeneous redox reaction at the aqueous chromium/magnetite interface. Colloids Surf A Physicochem Eng 107:77-88

Peterson ML, Brown GE, Parks GA, Stein CL (1997) Differential redox and sorption of $\mathrm{Cr}(\mathrm{III} / \mathrm{VI})$ on natural silicate and oxide minerals: EXAFS and XANES results. Geochim Cosmochim Acta 61:3399-3412

Roberts DR, Scheidegger AM, Sparks DL (1999) Kinetics of mixed Ni-Al precipitate formation on a soil clay fraction. Environ Sci Technol 33:3749-3754

Roberts DR, Ford RG, Sparks DL (2003) Kinetics and mechanisms of $\mathrm{Zn}$ complexation on metal oxides using EXAFS spectroscopy. J Colloid Interface Sci 263:364-376

Scheidegger AM, Sparks DL (1996) A critical assessment of sorption-desorption mechanisms at the soil mineral/water interface. Soil Sci 161:813-831

Scheidegger AM, Lamble GM, Sparks DL (1996) Investigation of $\mathrm{Ni}$ sorption on pyrophyllite: An XAFS study. Environ Sci Technol 30:548-554

Scheidegger AM, Lamble GM, Sparks DL (1997) Spectroscopic evidence for the formation of mixed-cation hydroxide phases upon metal sorption on clays and aluminum oxides. J Colloid Interface Sci 186:118-128

Scheidegger AM, Strawn DG, Lamble GM, Sparks DL (1998) The kinetics of mixed Ni-Al hydroxide formation on clay and aluminum oxide minerals: a time-resolved XAFS study. Geochim Cosmochim Acta 62:2233-2245

Schulze DG, Bertsch PM (1995) Synchrotron x-ray techniques in soil, plant, and environmental research. In: Sparks DL (ed) Advances in agronomy, vol 55. Academic Press, San Diego

Schulze DG, Stucki JW, Bertsch PM (eds) (1999) Synchrotron Xray Methods in Clay Science. The Clay Minerals Society, Boulder, CO.

Schumacher M, Christl I, Scheinost AC, Jacobsen C, Kretzschmar R (2005) Chemical heterogeneity of organic soil colloids investigated by scanning transmission X-ray microscopy and C-1 s NEXAFS microspectroscopy. Environ Sci Technol 39:9094-9100

Siebecker M, Li W, Khalid S, Sparks DL (2014) Rapid nickel-Al layered double hydroxide precipitation at the mineral-water interface measured in real time and at the molecular scale. Nature Communications (In press).

Singh B, Gräfe M, Kaur N, Liese A (2010) Applications of synchrotron-based $\mathrm{x}$-ray diffraction and $\mathrm{x}$-ray absorption spectroscopy to the understanding of poorly crystalline and metal-substituted iron oxides. In: Singh B, Gräfe M (eds) Synchrotron-based techniques in soils and sediments, developments in soil science. Elsevier, New York

Solomon D, Lehmann J, Kinyangi J, Liang BQ, Schafer T (2005) Carbon K-edge NEXAFS and FTIR-ATR spectroscopic investigation of organic carbon speciation in soils. Soil Sci Soc Am J 69:107-119

Solomon D, Lehmann J, Kinyangi J, Liang BQ, Heymann K, Dathe L, Hanley K, Wirick S, Jacobsen C (2009) Carbon (1 s) NEXAFS spectroscopy of biogeochemically relevant reference organic compounds. Soil Sci Soc Am J 73:18171830 
Solomon D, Lehmann J, de Zarruk KK, Dathe J, Kinyangi J, Liang BQ, Machado S (2011) Speciation and long- and short-term molecular-level dynamics of soil organic sulfur studied by Xray absorption near-edge structure spectroscopy. J Environ Qual 40:704-718

Sparks DL (2002) Environmental soil chemistry. Academic Press, San Diego

Sparks DL (2005a) Metal and oxyanion sorption on nautrally occurring oxide and clay mineral surfaces. In: Grassian VH (ed) Environmental catalysis. Taylor and Francis, Boca Raton

Sparks DL (2005b) Toxic metals in the environment: the role of surfaces. Elem 1:193-197

Sparks DL (2013) Advances in the use of synchrotron radiation to elucidate environmental interfacial reaction processes and mechanisms in the earth's critical zone. In: Xu J, Sparks DL (eds) Molecular environmental soil science. Springer, Dordrecht

Sparks DL, Ginder-Vogel M (2011) The role of synchrotron radiation in elucidating the biogeochemistry of metal(loids) and nutrients at critical zone interfaces. In: Huang PM, Li Y, Sumner ME (eds) Handbook of soil sciences: resource management and environmental impacts, 2nd edn. CRC Press, Boca Raton

Sparks DL (1989) Kinetics of Soil Chemical Processes. Academic Press, San Diego

Taylor RM (1984) The rapid formation of crystalline double hydroxy salts and other compounds by controlled hydrolysis. Clay Miner 19:591-603

Tejedor-Tejedor MI, Anderson MA (1990) Protonation of phosphate on the surface of goethite as studied by CIR-FTIR and electrophoretic mobility. Langmuir 6: 602-611
Thompson HA, Parks GA, Brown GE (1999a) Ambienttemperature synthesis, evolution, and characterization of cobalt-aluminum hydrotalcite-like solids. Clay Clay Miner 47:425-438

Thompson HA, Parks GA, Brown GE (1999b) Dynamic interactions of dissolution, surface adsorption, and precipitation in an aging cobalt(II)-clay-water system. Geochim Cosmochim Acta 63:1767-1779

Towle SN, Bargar JR, Brown GE Jr, Parks GA (1997) Surface precipitation of $\mathrm{Co}(\mathrm{II})(\mathrm{aq})$ on $\mathrm{Al}_{2} \mathrm{O}_{3}$. J Colloid Interface Sci 187:62-82

Voegelin A, Kretzschmar R (2005) Formation and dissolution of single and mixed $\mathrm{Zn}$ and Ni precipitates in soil: evidence from column experiments and extended X-ray absorption fine structure spectroscopy. Environ Sci Technol 39:5311-5318

Wan J, Tyliszczak T, Tokunaga TK (2007) Organic carbon distribution, speciation, and elemental correlations within soil micro aggregates: Applications of STXM and NEXAFS spectroscopy. Geochim Cosmochim Acta 71:5439-5449

Wang X, Li W, Harington R, Liu F, Parise J, Feng X, Sparks DL (2013) Effect of ferrihydrite crystallite size on phosphate adsorption reactivity. Environ Sci Technol 47:10322-10311

Wijnja H, Schulthess CP (2000) Vibrational spectroscopy study of selenate and sulfate adsorption mechanisms on $\mathrm{Fe}$ and $\mathrm{Al}$ (hydr)oxide surfaces. J Colloid Interface Sci 229:286-297

Zhang PC, Sparks DL (1990) Kinetics and mechanisms of sulfate adsorption desorption on goethite using pressure-jump relaxation. Soil Sci Soc Am J 54:1266-1273

Zhu M, Northrup P, Shi C, Billinge SJL, Sparks DL, Waychunas GA (2014) Structure of sulfate adsorption complexes on ferrihydrite. Environ Sci Technol Lett 1:97-101 